\title{
Ação da temperatura e luminosidade sobre a qualidade de azeite de oliva extravirgem produzido no Rio Grande do Sul
}

\author{
Effect of temperature and light on the quality of extra virgin olive oil produced in Rio Grande do \\ Sul \\ Efecto de la temperatura y la luz sobre la calidad del aceite de oliva virgen extra producido en Rio \\ Grande do Sul
}

\section{Resumo}

O objetivo do estudo visa a avaliação dos padrões de qualidade de azeites de oliva produzidos na região da Campanha do Rio Grande do Sul, frente ao armazenamento sob diferentes condições de luminosidade e temperatura. O delineamento experimental foi completamente casualizado em esquema trifatorial: incidência de temperatura (25 e $\left.30^{\circ} \mathrm{C}\right)$, incidência de luminosidade (0 e 300 Lux $)$ e tempo de armazenamento (0, 1, 2 e 3 meses), avaliando o índice de peróxidos; acidez livre; extinção específica no ultravioleta; clorofilas totais, atividade antioxidante; carotenoides totais; fenóis totais e avaliação sensorial. Obteve-se, acidez livre de $0,49 \mathrm{~g}$ ácido oleico. $100 \mathrm{~g}^{-1}$, índice de peróxidos de $7,90 \mathrm{mEq} \mathrm{O} 2 \cdot \mathrm{kg}^{-1}, \mathrm{~K}_{232}$ igual a 2,48, $\mathrm{K}_{270}$ igual a 0,15 , fenóis totais de 273,02 mg GAE.kg-1 , clorofilas totais de 37,72 mg feofitina $\alpha . \mathrm{kg}^{-1}$, atividade antioxidante de $24,39 \%$, carotenoides totais de $11,81 \mathrm{mg} \beta$-caroteno. $\mathrm{kg}^{-1}$, aroma com média geral igual a 6,75, sabor com 6,58 e intenção de compra de 3,75. A luminosidade influenciou aumentando os valores da acidez livre, extinção específica, diminuindo os de fenóis totais, carotenoides totais e clorofilas totais. A temperatura influenciou aumentando os valores de acidez livre, $\mathrm{K}_{232}$ e também diminuindo os de carotenoides totais e clorofilas totais. O tempo influenciou significativamente sobre todas as análises, exceto de fenóis totais, causando os mesmos efeitos de diminuição e aumento que luminosidade e temperatura sobre as análises. Tem-se com isso que a qualidade do azeite de oliva é afetada pela conjuntura de fatores de armazenamento adotada.

Palavras-chave: Armazenamento; Estabilidade; Antioxidante; Qualidade; Sensorial.

\begin{abstract}
The objective of the study is to evaluate the quality standards of olive oils produced in the Campanha region of Rio Grande do Sul, compared to storage under different conditions of light and temperature. The experimental design was completely randomized in a three-factor scheme: incidence of temperature $\left(25\right.$ and $\left.30^{\circ} \mathrm{C}\right)$, incidence of luminosity $(0$ and 300 Lux) and storage time (0,1, 2 and 3 months), evaluating the peroxide content; free acidity; specific quenching in the ultraviolet; total chlorophylls, antioxidant activity; total carotenoids; total phenols and sensory
\end{abstract}


evaluation. It was obtained, free acidity of $0.49 \mathrm{~g}$ oleic acid. $100 \mathrm{~g}^{-1}$, peroxide index of $7.90 \mathrm{mEq} \mathrm{O}$. $\mathrm{kg}^{-1}, \mathrm{~K}_{232}$ equal to $2.48, \mathrm{~K}_{270}$ equal to 0.15 , total phenols of $273.02 \mathrm{mg} \mathrm{GAE} . \mathrm{kg}^{-1}$, total chlorophylls of $37.72 \mathrm{mg}$ phaeophytin $\alpha . \mathrm{kg}^{-1}$, antioxidant activity of $24.39 \%$, total carotenoids of $11.81 \mathrm{mg} \beta$-carotene. $\mathrm{kg}^{-1}$, aroma with average overall equal to 6.75 , flavor with 6.58 and purchase intent of 3.75. The luminosity influenced increasing the values of free acidity, specific extinction, decreasing the values of total phenols, total carotenoids and total chlorophylls. The temperature influenced increasing the values of free acidity, $\mathrm{K}_{232}$ and also decreasing the values of total carotenoids and total chlorophylls. Time significantly influenced all analyses, except for total phenols, causing the same decrease and increase effects as light and temperature on the analyses. It follows that the quality of olive oil is affected by the conjuncture of storage factors adopted.

Keywords: Storage; Stability; Antioxidant; Quality; Sensory.

\section{Resumen}

El objetivo del estudio es evaluar los estándares de calidad de los aceites de oliva producidos en la región de Campanha de Rio Grande do Sul, en comparación con el almacenamiento en diferentes condiciones de luz y temperatura. El diseño experimental fue completamente al azar en un esquema de tres factores: incidencia de temperatura $\left(25\right.$ y $\left.30^{\circ} \mathrm{C}\right)$, incidencia de luminosidad $(0$ y $300 \mathrm{Lux})$ y tiempo de almacenamiento $(0,1,2$ y 3 meses), evaluando el peróxido contenido; acidez libre; extinción específica en el ultravioleta; clorofilas totales, actividad antioxidante; carotenoides totales; fenoles totales y evaluación sensorial. Se obtuvo, acidez libre de $0.49 \mathrm{~g}$ ácido oleico. $100 \mathrm{~g}^{-1}$, índice de peróxidos de $7.90 \mathrm{mEq} \mathrm{O} 2 \cdot \mathrm{kg}^{-1}, \mathrm{~K}_{232}$ igual a $2.48, \mathrm{~K}_{270}$ igual a 0.15 , fenoles totales de 273.02 mg GAE. $\mathrm{kg}^{-1}$, total clorofilas de $37.72 \mathrm{mg}$ feofitina $\alpha . \mathrm{kg}-1$, actividad antioxidante de $24.39 \%$, carotenoides totales de $11.81 \mathrm{mg} \beta$-caroteno. $\mathrm{kg}^{-1}$, aroma con promedio general igual a 6.75, sabor con 6.58 e intención de compra de 3.75 . La luminosidad influyó aumentando los valores de acidez libre, extinción específica, disminuyendo los valores de fenoles totales, carotenoides totales y clorofilas totales. La temperatura influyó aumentando los valores de acidez libre, $\mathrm{K}_{232} \mathrm{y}$ también disminuyendo los valores de carotenoides totales y clorofilas totales. El tiempo influyó significativamente en todos los análisis, a excepción de los fenoles totales, causando los mismos efectos de disminución y aumento que la luz y la temperatura en los análisis. De ello se deduce que la calidad del aceite de oliva se ve afectada por la coyuntura de factores de almacenamiento adoptada.

Palabras clave: Almacenamiento; Estabilidad; Antioxidante; Calidad; Sensorial.

\section{Introdução}

A Oliveira (Olea europaea L.), é uma das frutíferas mais antigas cultivadas, sendo a única de sua espécie com frutos comestíveis, a azeitona, que servem como matéria-prima para a extração de azeite e para a produção de azeitona em conserva. (Coutinho \& Jorge, 2007). No Brasil a cultura da oliveira foi introduzida em quase todos os estados do país, sendo encontrada em maior proporção no Sul e Sudeste. As áreas de plantio comerciais concentram-se nos estados do Rio Grande do Sul, Minas Gerais e em Santa Catarina (Coutinho, 2007). O Conselho Oleícola Internacional (COI) não dispõe de dados sobre a balança comercial de produção e exportação de azeites de oliva em terras brasileiras, com conhecimento, contudo, de que o consumo no ano/safra de 2019/2020 foi de 104 mil toneladas de azeite de oliva (Conselho Oleícola Internacional, 2021).

O azeite de oliva é um líquido amarelo-esverdeado, aromático e transparente, presente na culinária desde eras rudimentares (Mello \& Pinheiro, 2012). É produzido a partir de frutas frescas e saudáveis exclusivamente por processos mecânicos e físicos, ao contrário de outros óleos comestíveis, como óleos de girassol e soja, que precisam ser refinados antes do consumo (Conselho Oleícola Internacional, 2021). Os processos de extração típicos para a extração do azeite baseiam-se geralmente na prensagem tradicional, no sistema trifásico ou na abordagem centrífuga de duas fases desenvolvida mais recentemente (Ochando-Pulido et al., 2020).

Nos últimos anos, fato inegável é a posição de destaque que o azeite de oliva vem angariando, sobretudo, por suas características sensoriais diferenciadas dos demais azeites e também pelos inúmeros e comprovados benefícios à saúde aliados ao consumo direto. Os principais promotores dos benefícios do azeite de oliva são o perfil de ácidos graxos, presença de inúmeros compostos bioativos como tocoferóis, fosfolipídeos e compostos fenólicos. Notadamente as principais propriedades funcionais são atreladas à composição fenólica por sua atividade anti-inflamatória e antioxidante (Bakhouche et al., 2015; Gorzynik-Debicka et al., 2018). Porém, esta qualidade, pode ser impactada por alguns fatores pós processamento, afetando sua estabilidade, como é o caso da presença de luminosidade, oxigênio e calor, ocasionando a redução das características 
nutricionais e sensoriais. Por tal motivo, a vida de prateleira do produto deve estar atrelada a práticas de armazenamento que garantam a longevidade dos compostos ditos benéficos ao consumidor. De igual forma a preservação das características sensoriais são esperadas como sendo de alta qualidade durante o período de estocagem e o tempo de consumo (Ayton et al., 2012).

Segundo a legislação, os requisitos de qualidade do azeite de oliva são estipulados em vista do percentual de acidez livre, extinção específica no ultravioleta e índice de peróxidos (Brasil, 2012). Além das análises físico químicas obrigatórias, em alguns países é obrigatório a comprovação da qualidade do azeite através de análises sensoriais, estas análises são realizadas por grupo de julgadores intitulado Panel Test, composto por 8 a 12 julgadores treinados e qualificados, visto que apenas os testes sensoriais, conseguem avaliar os efeitos combinados dos compostos que formam aromas e sabores complexos, por meio de estímulos perceptíveis aos sentidos humanos: olfativo, paladar e tátil (Bertoncini \& Testa, 2014).

O presente estudo teve como objetivo a avaliação dos padrões de qualidade estipulados pela legislação brasileira para azeites de oliva produzidos na região da Campanha do Rio Grande do Sul, bem como a realização de análise sensorial e determinação de compostos antioxidantes, frente ao armazenamento sob diferentes condições, justificada pela inexistência de estudos deste caráter com azeites da região e pela adição de um parâmetro avaliativo para classificação do azeite não estipulado pela legislação, mas sendo de suma importância na separação de tipos de azeites.

\section{Metodologia}

\subsection{Amostras}

Foram utilizadas amostras de azeite de oliva extravirgem sendo as azeitonas cultivadas e processadas na região de

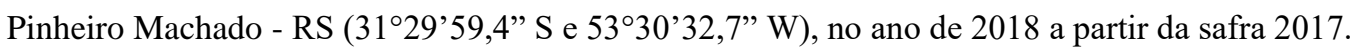

\subsection{Delineamento experimental}

O delineamento experimental foi completamente casualizado, composto de três repetições. O experimento foi realizado em esquema trifatorial, no qual o fator A será a incidência de temperatura $\left(23\right.$ e $30^{\circ} \mathrm{C}$ ), o fator $\mathrm{B}$ incidência de luminosidade ( 0 e 300 Lux) e o fator $\mathrm{C}$ tempo de armazenamento ( $0,1,2$ e 3 meses). O experimento constou de 16 amostras com determinações em triplicata, perfazendo um total de 384 determinações.

Os níveis das variáveis foram escolhidos da seguinte maneira: A temperatura de $23^{\circ} \mathrm{C}$ representa a temperatura ambiente que o azeite fica exposto nos supermercados, ao passo que os $30^{\circ} \mathrm{C}$ forma escolhidos em razão da temperatura elevada do verão da cidade de Bagé e consequentemente também nestes ambientes. Já a luminosidade escolhida foi a ausência (0 Lux), a qual é recomendada para todo azeite de oliva extravirgem e 300 Lux foi fixada como presença de luminosidade e também é a luminosidade média que os azeites recebem nas gôndolas de supermercados. O tempo de armazenamento correspondeu ao tempo em média em que os azeites ficam nas gôndolas de supermercado até a compra.

\subsection{Determinações analíticas}

A partir das metodologias propostas pelo Instituto Adolfo Lutz (2008), foi determinado o índice de peróxidos, sendo expresso em miliequivalentes de oxigênio reativo por quilograma $(\mathrm{kg})$ de amostra (meq $\mathrm{O}_{2} \cdot \mathrm{kg}^{-1}$ ); o índice de acidez (IA), expresso em gramas de ácido oleico por $100 \mathrm{~g}$ de amostra (g.100 $\left.{ }^{-1}\right)$; foi determinada também a determinação da extinção específica por absorção na região do ultravioleta nos comprimentos de onde de 270 e $232 \mathrm{~nm}$.

O teor de clorofilas totais foi determinado através da metodologia proposta por Pokorny et al. (1995), com amostra medida nos comprimentos de onda de 630, 670 e 710 e conteúdo de clorofilas determinado através da Equação 1 e expresso em mg feofitinas. $\mathrm{kg}^{-1}$. 


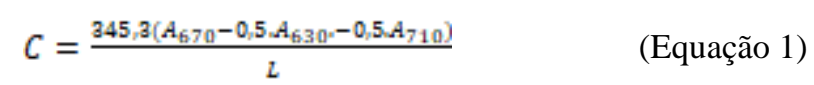

A capacidade antioxidante foi determinada através da capacidade dos compostos presentes nas amostras em sequestrar o radical estável DPPH (2,2-difenil-1-picrilhidrazila), segundo método descrito por Brand-Williams et al. (1995). Para a realização da análise utilizou-se um extrato metanólico e a amostra medida no comprimento de onda $517 \mathrm{~nm}$. O resultado foi expresso em porcentagem de inibição de acordo com a Equação 2.

$$
\% I=\frac{A_{\text {branco }}-A_{\text {mansirna }}}{A_{\text {brumes }}}
$$

O teor de carotenoides totais foi determinado segundo metodologia descrita por Rodriguez-Amaya (2001), sendo o extrato da amostra medido em um comprimento de onda de $450 \mathrm{~nm}$ e obtido através da Equação 3 . O resultado expresso em $\mathrm{mg} \beta$-caroteno. $\mathrm{kg}^{-1}$.

$$
C T=\frac{\left.A_{4780} \cdot 50 \cdot 10^{\mathrm{fi}}\right)}{2500 \cdot 100 \mathrm{~m}} \quad \text { (Equação 3) }
$$

Para determinação de fenóis totais utilizou-se a metodologia descrita por Singleton \& Rossi (1965), utilizando extrato metanólico. Sendo resultado foi expresso em mg. $\mathrm{Kg}^{-1} \mathrm{de}$ ácido gálico. A leitura de absorbância da amostra foi realizada a 765 $\mathrm{nm}$ e o resultado expresso em $\mathrm{mg} . \mathrm{Kg}^{-1} \mathrm{de}$ ácido gálico.

\subsection{Análise sensorial}

Nos testes sensoriais utilizou-se metodologia adaptada do Instituto Adolfo Lutz (2008) para teste de aceitabilidade e o teste de escala de atitude ou intenção de compra. Participaram da análise, 40 julgadores não treinados e consumidores de azeite. As amostras foram oferecidas ao julgador em cabine sensorial apropriada para o teste.

\subsection{Análise estatística}

Os resultados foram avaliados através da análise de variância (ANOVA) e pelo teste de Tukey, ao nível de 5\% de significância para os fatores em estudo e a significância de comparação com a amostra controle foi realizada atráves de teste Dunnett a $5 \%$, todos em programa estatístico.

\section{Resultados e Discussão}

\subsection{Determinações analíticas}

Os resultados das análises dos parâmetros de qualidade realizadas no azeite de oliva extravirgem estão apresentados na Tabela 1 . 
Tabela 1. Análises de qualidade da amostra controle.

\begin{tabular}{|c|c|c|}
\hline \multirow{2}{*}{$\begin{array}{l}\text { Acidez livre (g ácido oleico. } 100 \mathrm{~g}^{-1} \text { ) } \\
\text { Índice de peróxidos }\left(\mathrm{mEq} \mathrm{O}_{2 .} \mathrm{kg}^{-1} \text { ) }\right.\end{array}$} & \multicolumn{2}{|r|}{$0,49 \pm 0,03$} \\
\hline & & $7,90 \pm 0,14$ \\
\hline \multirow{3}{*}{ Extinção específica $\left(M^{-1} \cdot \mathrm{cm}^{-1}\right)$} & 232 & $2,48 \pm 0,15$ \\
\hline & & \\
\hline & 270 & $0,15 \pm 0,01$ \\
\hline
\end{tabular}

Fonte: Autores.

Os parâmetros de qualidade analisados se encontram dentro dos limites estabelecidos pela legislação brasileira vigente para azeite de oliva extravirgem, abaixo dos valores encontrado por Mello e Pinheiro (2012) para azeites da cultivar Arbequina da região de Cachoeira do Sul - RS e também abaixo dos valores encontrados por Cardoso et al. (2010) para acidez livre e índice de peróxidos em azeites de oliva de diferentes cultivares produzidos na região de Minas Gerais, tal fato indica os parâmetros de processamento bem empregados pela empresa produtora do azeite em questão.

Salienta-se ainda que os valores estão dentro dos patamares encontrados por Silva et al. (2012) no estudo de variação de qualidade em 32 cultivares de oliveira, e próximos dos encontrados por Rodrigues (2015) para uma categoria de blend produzido na Serra da Mantiqueira-MG.

Os resultados das análises fitoquímicas realizadas no azeite de oliva extravirgem estão apresentados na Tabela 2.

Tabela 2. Análises fitoquímicas da amostra controle.

\begin{tabular}{ll}
\hline Fenóis totais $\left(\mathbf{m g} \mathbf{G A E} . \mathbf{k g}^{-\mathbf{1}}\right)$ & $273,02 \pm 0,98$ \\
\hline Carotenoides totais $(\mathbf{m g} \boldsymbol{\beta}$-caroteno.kg-1) & $11,81 \pm 0,75$ \\
\hline Clorofilas totais $\left(\mathbf{m g}\right.$ feofitina $\left.\boldsymbol{\alpha} \cdot \mathbf{k g}^{-\mathbf{1}}\right)$ & $37,72 \pm 0,47$ \\
\hline Atividade antioxidante $(\boldsymbol{\%}$ inibição) & $24,39 \pm 0,54$ \\
\hline
\end{tabular}

Fonte: Autores.

Os resultados obtidos para fenóis totais são similares aos encontrados por Boskou (2006), que se encontram entre 200 a $500 \mathrm{mg} \mathrm{GAE} . \mathrm{Kg}^{-1}$ para variedades espanholas, superior aos encontrados por Vichi et al. (2003) com teor de polifenóis totais de $193 \mathrm{mg} \mathrm{GAE.} \mathrm{Kg}^{-1}$ para azeites italianos e também superior a Rodeghiero (2016) que encontrou teores de 61,81 a 156,74 mg GAE. $\mathrm{Kg}^{-1}$ na determinação de compostos fenólicos para azeites produzidos nas cidades de Pelotas, Bagé e Uruguaiana no Rio Grande do Sul. A variação no conteúdo polifenólico deve-se principalmente as variedades utilizadas na fabricação de azeites tipo blend, além de grau de maturação de frutos, condições edafoclimáticas, condições de processamento, manejo de campo e finalidade, além do que em estudo realizado por Jorge (2010) sobre caracterização de azeites virgem extra "gourmet" varietais e "blends" observou-se que os azeites "gourmet" varietais possuíram teores de polifenóis maiores do que em "blends" da mesma origem.

Os valores de carotenoides totais do presente estudo são superiores aos encontrados por Jorge (2010) que variou entre 2,09 a 8,37 mg. $\mathrm{Kg}^{-1}$, Rodeghiero (2016) de 1,82 a 7,88 mg. $\mathrm{Kg}^{-1}$, abarcados pela faixa encontrada por Reboredo-Rodríguez (2016) de 10 a 12 mg. $\mathrm{Kg}^{-1}$ para variedades de azeites espanhóis e próximos de Dabbou et al. (2010) de 11,99 a 20 mg.Kg-1 para cultivares de Arbequina, Coratina e Koroneiki cultivadas na Tunísia. 
O teor de clorofilas totais mostrou-se superior aos encontrados por Manai-Djebali et al. (2012) que obteve valores entre 1,15 a 6,22 mg. $\mathrm{Kg}^{-1}$ para azeites produzidos na Tunísia, Silva (2011) que apresentou um teor de $19,14 \mathrm{mg} \mathrm{Kg}^{-1}$ para amostra de azeite português, Reboredo-Rodríguez (2016) que encontrou valores entre 15 a 22 mg. $\mathrm{Kg}^{-1}$, Jorge (2010) de 2,28 a 16,24 mg. Kg ${ }^{-1}$ e Oliveira (2014) de 2,15 a 9,66, apresentando então um alto teor de clorofilas. Segundo Morales e Przybylski (2003) a estabilidade oxidativa do azeite de oliva é fortemente afetada em presença de clorofilas e derivados, uma vez que estes são pigmentos fotossintetizantes em presença de luminosidade.

A porcentagem de inibição da atividade antioxidante da amostra foi superior a encontrada por Dias et al. (2017) de 5,93\% e Andrade et al. (2017) de 6,03 para azeites produzidos na Campanha do Rio Grande do Sul, próxima da faixa encontrada por Martins (2015) de 25 a 60\% para azeites monovarietais produzidos em Portugal e abaixo de Laincer et al. (2014) com faixa de 36,57 a 72,20\% para azeites produzidos na Argélia.

\subsection{Análise sensorial}

Os resultados obtidos para a análise sensorial da amostra controle podem ser observados na Tabela 3.

Tabela 3. Teste de aceitabilidade e intenção de compra.

\begin{tabular}{lll}
\hline \multirow{2}{*}{ Aceitabilidade } & Aroma & $6,75 \pm 1,99$ \\
\cline { 2 - 3 } & Sabor & $6,58 \pm 1,84$ \\
\hline Intenção de compra & & $3,75 \pm 0,96$ \\
\hline
\end{tabular}

Fonte: Autores.

A amostra controle apresentou aceitabilidade do aroma entre os pontos 6 (gostei ligeiramente) e 7 (gostei regularmente), ficando mais próxima da nota 7 , o que denota que os julgadores gostaram regularmente da amostra. Já quanto ao sabor, os julgadores também demonstraram aceitabilidade entre os pontos 6 e 7, porém com menor tendência ao 7 .

A nota atribuída à intenção de compra da amostra está entre os pontos 3 (tenho dúvidas se compraria) e 4 (provavelmente compraria), ficando mais próxima do 4. Em algumas fichas de análise sensorial, pode-se perceber a preocupação quanto ao preço de uma garrafa de azeite sendo um fator conflitante no momento da compra por parte dos consumidores.

\subsection{Influência do tempo, temperatura e luminosidade}

\subsubsection{Acidez livre}

Como pode-se observar através da Tabela 4, quando os tratamentos foram avaliados somente quanto a luminosidade e temperatura, tais fatores foram significativos para o teste Tukey a 5\%. De igual forma através da adição do fator tempo, mostrado na Figura 1 pelo Diagrama de Pareto pode-se avaliar a significância das variáveis tempo, temperatura e luminosidade durante todo o intervalo de realização de experimento, sendo o tempo de armazenamento o fator mais agravante no incremento do valor da acidez, seguido de luminosidade e temperatura. 
Research, Society and Development, v. 11, n. 2, e31311225685, 2022

(CC BY 4.0) | ISSN 2525-3409 | DOI: http://dx.doi.org/10.33448/rsd-v11i2.25685

Tabela 4. Influência da temperatura e luminosidade sobre acidez livre.

\begin{tabular}{|c|c|c|c|c|c|c|c|c|c|}
\hline \multirow{2}{*}{\multicolumn{2}{|c|}{$\begin{array}{c}\text { Dias } \\
\text { Luminosidade (Lux) }\end{array}$}} & \multirow{2}{*}{\multicolumn{2}{|c|}{\begin{tabular}{|l}
\multicolumn{2}{|c}{ Zero } \\
$0 \quad 300$
\end{tabular}}} & \multicolumn{2}{|c|}{30} & \multicolumn{2}{|c|}{60} & \multicolumn{2}{|c|}{90} \\
\hline & & & & 0 & 300 & 0 & 300 & 0 & 300 \\
\hline \multirow{2}{*}{$\begin{array}{l}\text { Temperatura } \\
\left({ }^{\circ} \mathbf{C}\right)\end{array}$} & 23 & \multirow{2}{*}{\multicolumn{2}{|c|}{$0,49 \pm 0,03$}} & $0,53 \pm 0,03 \mathrm{Ab}$ & $0,64 \pm 0,06 * \mathrm{Aa}$ & $0,62 \pm 0,01 * \mathrm{Ba}$ & $0,74 \pm 0,04 * \mathrm{Aa}$ & $0,65 \pm 0,02 * \mathrm{Bb}$ & $0,75 \pm 0,01 * \mathrm{Aa}$ \\
\hline & 30 & & & $0,66 \pm 0,01 * \mathrm{Aa}$ & $0,68 \pm 0,04 * \mathrm{Aa}$ & $0,69 \pm 0,04 * \mathrm{Ba}$ & $0,80 \pm 0,02 * \mathrm{Aa}$ & $0,69 \pm 0,01 * \mathrm{Ba}$ & $0,80 \pm 0,04 * \mathrm{Aa}$ \\
\hline
\end{tabular}

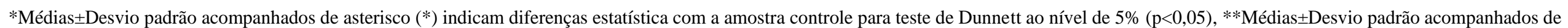

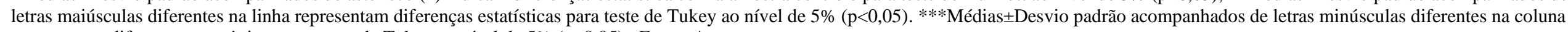
representam diferenças estatísticas para teste de Tukey ao nível de $5 \%(\mathrm{p}<0,05)$. Fonte: Autores. 
Figura 1. Diagrama de Pareto para influência do tempo, temperatura e luminosidade sobre acidez livre.

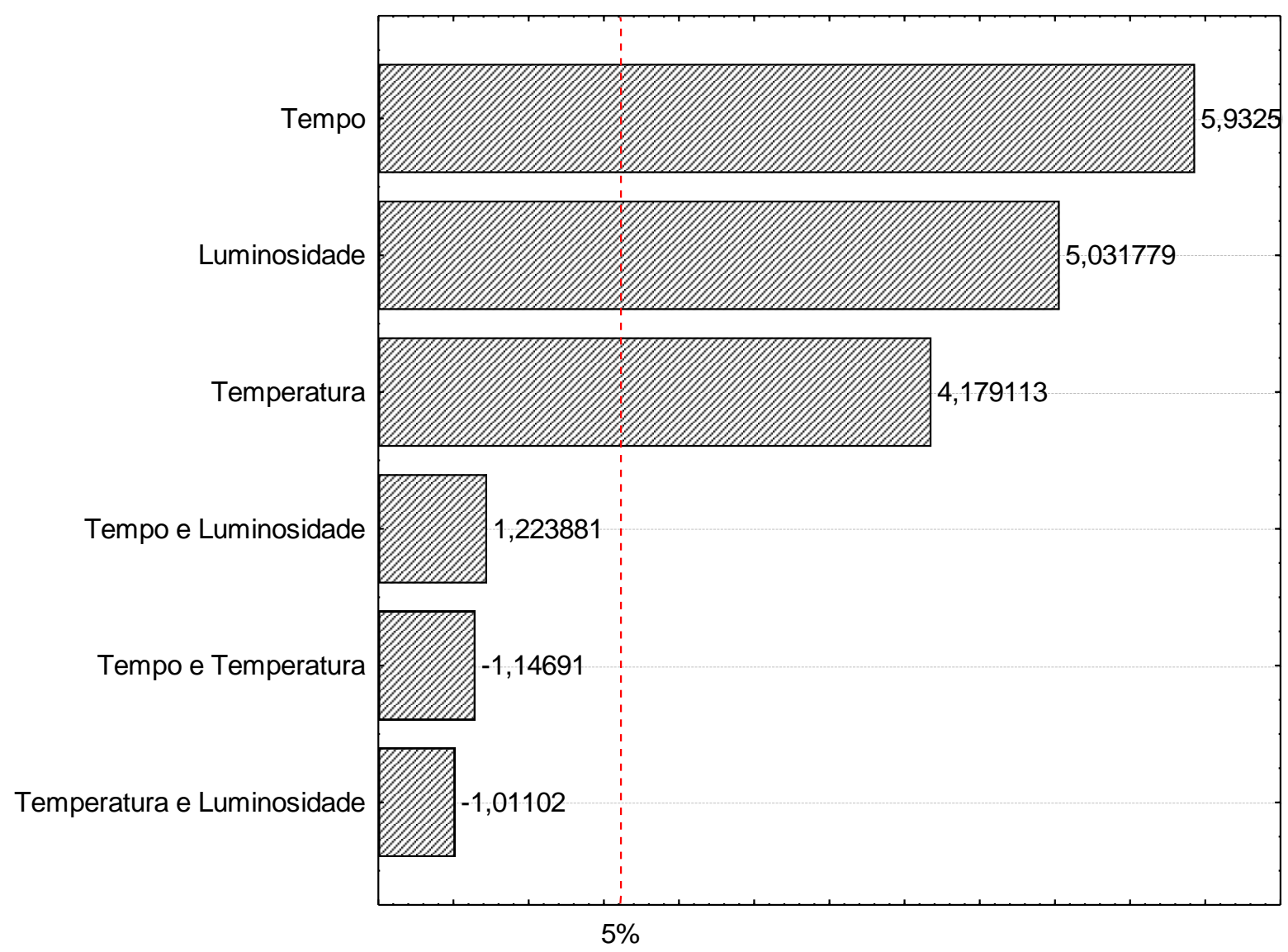

Fonte: Autores.

Segundo Silva et al. (2012) o índice de acidez está relacionado a diversos fatores como o tempo de estocagem, a maturação das azeitonas no momento da colheita, ação enzimática e os meios empregados para o processamento do azeite (prensagem ou centrifugação). Além disso a vida útil de um azeite que normalmente não excede os 18 meses, sendo que isto também depende do tipo de embalagem ou recipiente no qual está inserido, sendo a auto-oxidação e a foto-oxidação os principais mecanismos de deterioração. Ademais o tempo de armazenamento pode propiciar a ação da acil hidrolase que hidrolisa os triglicerídeos e fosfolipídeos a ácidos graxos, com isso aumentando a medida de acidez (Silva, 2011).

O aumento da acidez livre em função da luminosidade e temperatura pode ser explicado pela ocorrência de hidrólise de triacilgliceróis e oxidação (foto-oxidação e auto-oxidação). As reações hidrolíticas são impulsionadas pelo aumento de temperatura auxiliando na formação de ácidos graxos livres, di e monoacilgliceróis. Já a foto-oxidação lipídica é ligada à reação de oxigênio atmosférico em difusão no azeite com moléculas fotossensíveis como clorofila que auxiliam na formação de oxigênio singlete (Freire et al., 2013). Esse processo de hidrólise é acelerado em função da velocidade de reação que é afetada de proporcionalmente ao aumento de temperatura. Isso deve-se ao fato de que com o aumento da temperatura do sistema há maior agitação de partículas reagentes e aumento de energia cinética. Sendo assim, mais colisões ocorrerão e com aumento de energia incrementa-se o número de partículas que reagirão e consequentemente a reação ocorrerá de forma mais rápida do que em temperaturas menores (Fogaça, 2021). 


\subsection{2 Índice de peróxidos}

De acordo com a Tabela 5 não houveram diferenças significativas para Tukey a 5\% quando avaliados individualmente os efeitos da luminosidade e temperatura em cada intervalo de tempo, porém de acordo com a Figura 2 a variável tempo influenciou proporcionando o aumento do índice de peróxido nas amostras analisadas.

Figura 2. Diagrama de Pareto para influência do tempo, temperatura e luminosidade sobre índice de peróxidos.

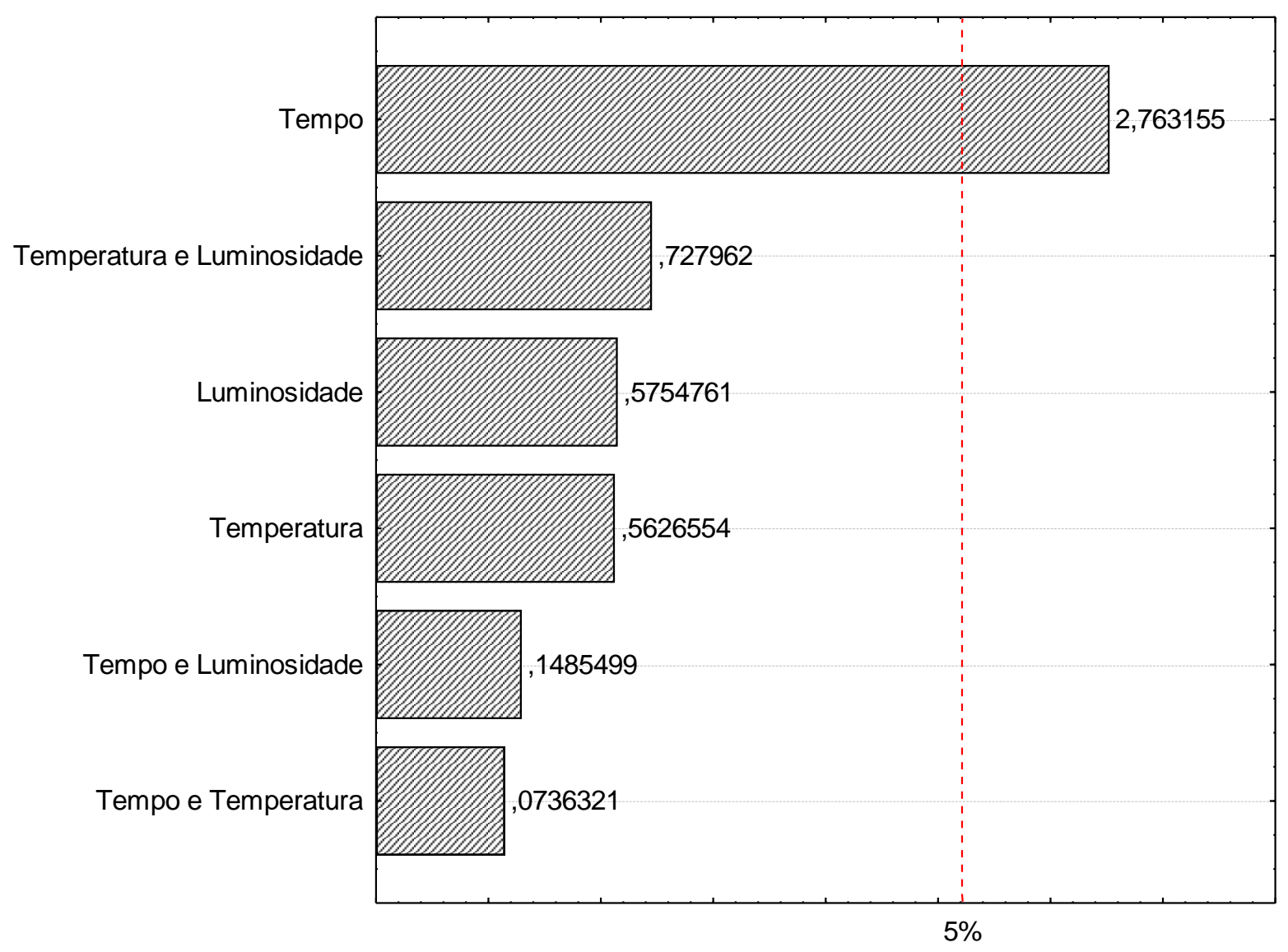

Fonte: Autores.

Tal fato aconteceu em decorrência da formação de peróxidos estar intimamente ligada ao aumento da acidez livre, uma vez que os ácidos graxos livres formados servem como meio para surgimento dos radicais peróxidos no decorrer do tempo. Neste caso a energia de ativação necessária para o início do surgimento dos primeiros radicais livres, pode ser fornecida através de um viés energético de aumento de temperatura, radiação e oxigênio singlete (Silva, 2011).

Os ácidos graxos insaturados, sobretudo di e tri-insaturados, presentes naturalmente no azeite ou por meio de hidrólise de triacilgliceróis, são mais facilmente convertidos em radicais livres que ácidos graxos saturados, visto que um átomo de hidrogênio é retirado de forma mais eficaz da molécula caso a ligação dupla esteja localizada no átomo de carbono adjacentes. Ademais, necessita-se ainda, de uma carga energética substancialmente menor para produção de radicais livres a partir de produtos de oxidação lipídica. O oxigênio reage facilmente com o carbono livre da molécula lipídica formando um radical peróxido. Os radicais peróxidos possuem grande quantidade energética, retirando um átomo de hidrogênio da molécula lipídica, com isso o radical peroxil converte-se em uma molécula de hidroperóxido, produzindo outro radical lipídico. Tal processo pode-se repetir inúmeras vezes no decorrer de um curto espaço de tempo (Kamal-Eldin \& Pokorny, 2005). 
Os mecanismos de foto-oxidação e auto-oxidação são mencionados como meios para aumento do índice de peróxidos, sobretudo, a foto-oxidação ocorre de forma mais eficaz na presença de sensibilizadores como clorofilas e feofitinas, auxiliando na formação de oxigênio singlete. Salienta-se que as amostras em questão apresentam índices bem elevados destes dois pigmentos cloroplásticos quando comparados a outros azeites de oliva. De igual forma, a concentração de oxigênio dissolvido no azeite é dependente da concentração de oxigênio no headspace da embalagem, uma vez que quanto maior a concentração de oxigênio no headspace, maior a dissolução deste no óleo, propiciando aumento da taxa de oxidação durante o tempo. O oxigênio se intensifica no azeite através de difusão durante o armazenamento, uma vez que este não é agitado (Choe et al., 2005). 
Research, Society and Development, v. 11, n. 2, e31311225685, 2022

(CC BY 4.0) | ISSN 2525-3409 | DOI: http://dx.doi.org/10.33448/rsd-v11i2.25685

Tabela 5. Influência da temperatura e luminosidade sobre índice de peróxidos.

Dias

Zero

30

60

90

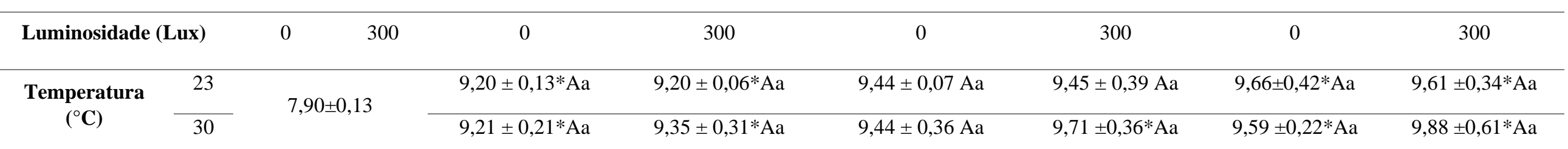

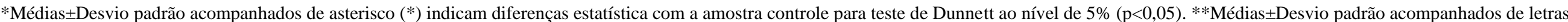

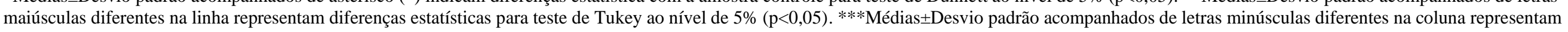
diferenças estatísticas para teste de Tukey ao nível de 5\% $(\mathrm{p}<0,05)$. Fonte: Autores. 


\subsubsection{Extinção específica no ultravioleta}

Através da Tabela 6 pode-se observar que quando avaliados os efeitos individuais da temperatura e luminosidade sobre a extinção específica a $232 \mathrm{~nm}$ houve diferenças significativas para Tukey a 5\% dos valores expostos a maior temperatura e luminosidade. Fato corroborado quando se inclui o tempo de armazenamento e os resultados são avaliados através do Diagrama de Pareto da Figura 3 pelo qual obtém-se que os fatores que influenciaram foram sobretudo a luminosidade, tempo e temperatura, não havendo interação entre eles.

Figura 3. Diagrama de Pareto para influência do tempo, temperatura e luminosidade sobre extinção específica a $232 \mathrm{~nm}$.

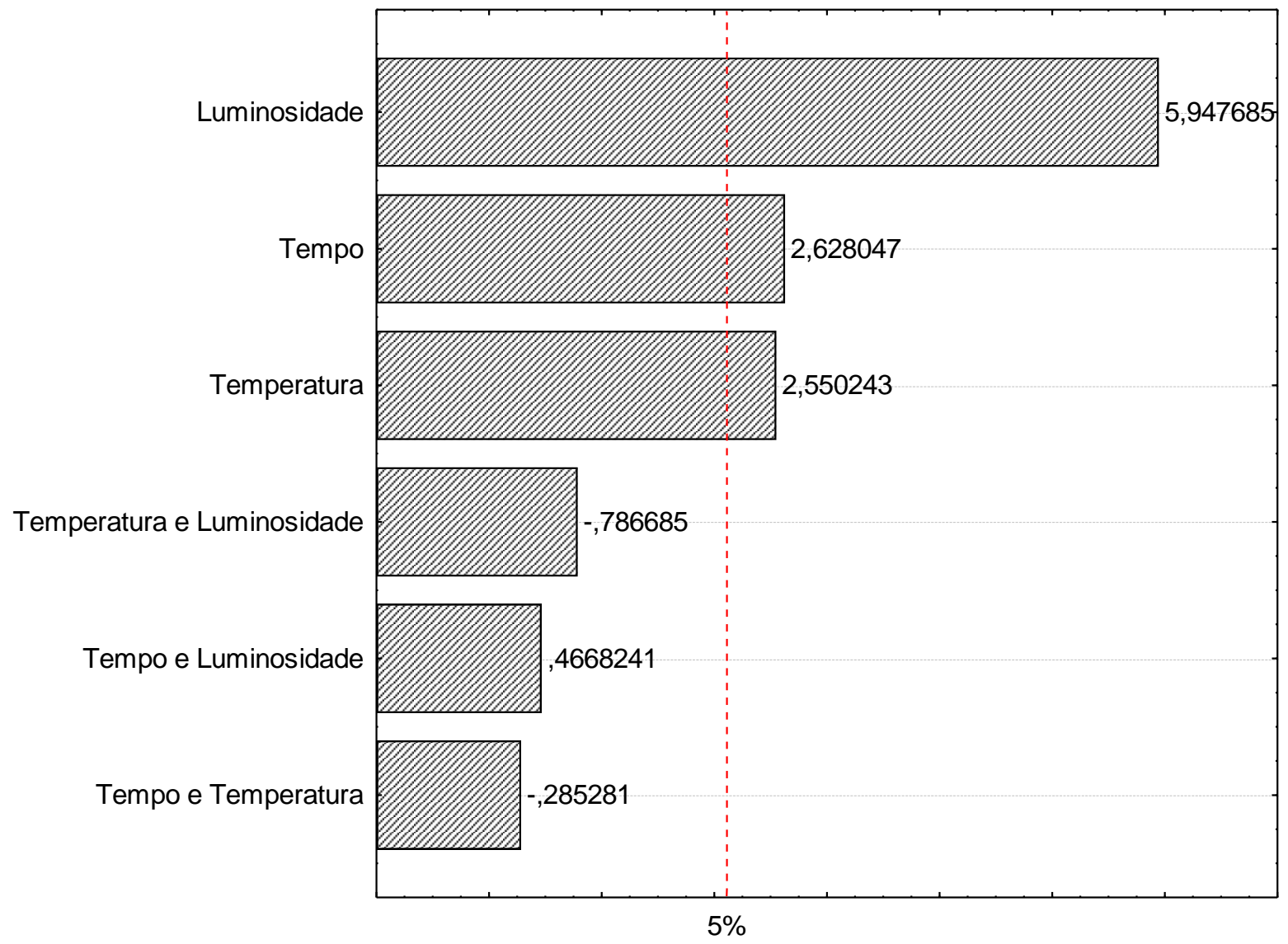

Fonte: Autores.

Já observando a Tabela 7, pode-se constatar que quando analisados individualmente luminosidade e temperatura em cada intervalo de tempo, somente a luminosidade é significativa a Tukey $5 \%$ para extinção específica a $270 \mathrm{~nm}$. Porém ao inclui-se o tempo de armazenamento e suas implicações pode-se observar que de acordo com a Figura 4 os fatores que obtiveram diferença estatística ao nível de $5 \%$ foram luminosidade, tempo e a interação entre tempo e temperatura. 
Figura 4. Diagrama de Pareto para influência do tempo, temperatura e luminosidade sobre a extinção específica a 270 nm.

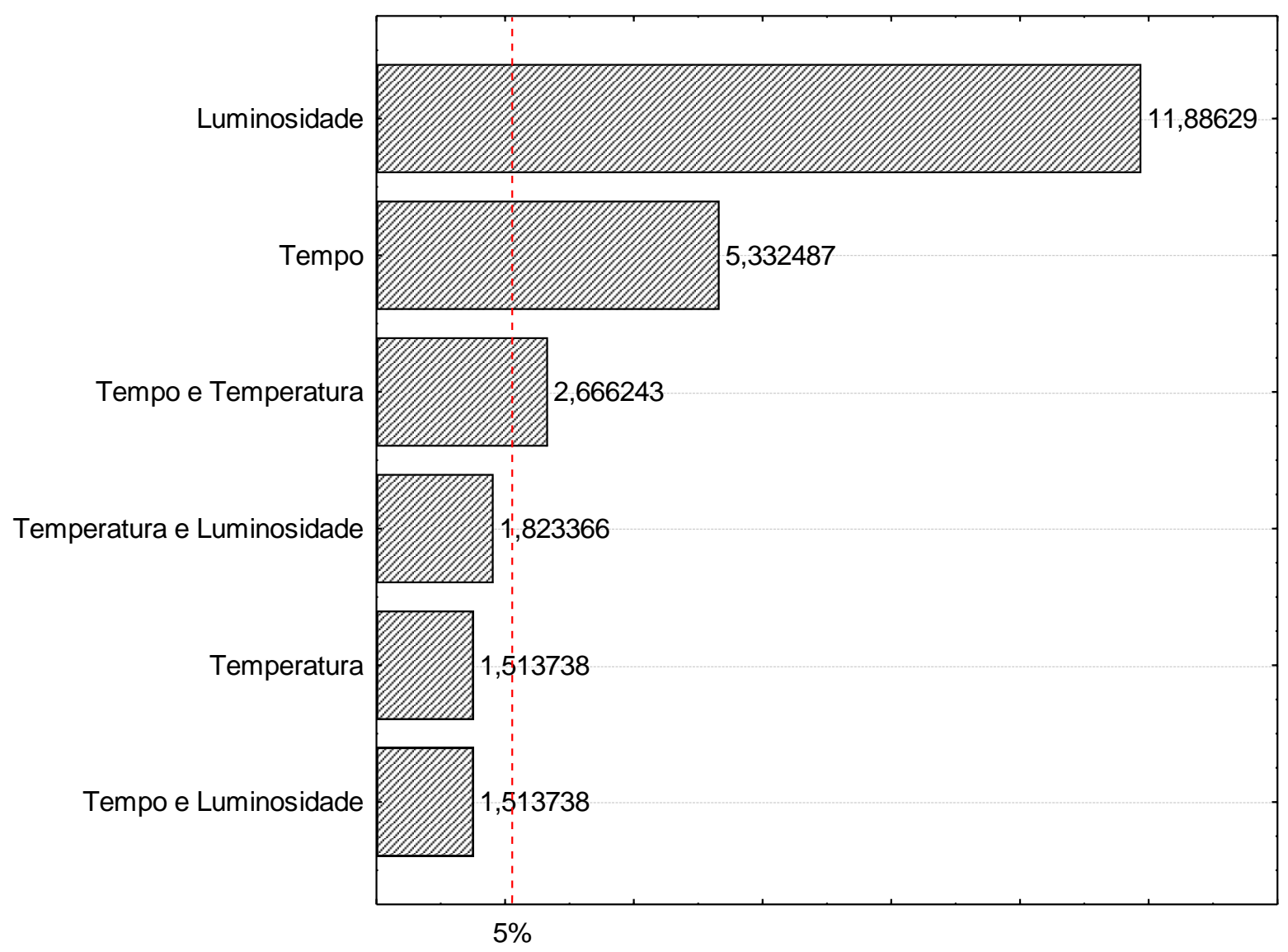

Fonte: Autores.

Segundo Herrera e Dueñas (2008) a extinção específica no ultravioleta a $232 \mathrm{~nm}$ é uma medida parecida ao índice de peróxidos, uma vez que através dela é possível detectar a oxidação inicial do azeite. A oxidação de ácidos graxos livres poliinsaturados ocorre quase que concomitantemente a formação dos hidroperóxidos e rearranjo de duplas ligações, o qual dá origem aos dienos conjugados que absorvem tal comprimento de onda. Ao passo que a $270 \mathrm{~nm}$ consegue-se detectar um estado oxidativo mais avançado, visto que a medida em que há avanço do processo oxidativo no armazenamento (tempo) catalisado pela presença da luminosidade ocorre a modificação dos dienos conjugados, levando-se à obtenção de componentes como alfadicetonas ou cetonas insaturadas que absorvem em comprimento de onda $(270 \mathrm{~nm})$ diferente de hidroperóxidos (Herrera \& Duñas, 2008; Silva et al., 2012).

Os mecanismos responsáveis pelo incremento no valor das duas extinções específicas já citados são a foto-oxidação e autoxidação, sendo a foto-oxidação catalisada em presença de agentes sensibilizadores como clorofila em presença de radiação UV, levando então a formação de compostos secundários da degradação de hidroperóxidos que originam posteriormente álcoois, aldeídos e hidrocarbonetos responsáveis pelo off flavour do azeite. Já a autoxidação é um processo mais dinâmico que evolui ao longo do tempo e depende do tipo de ação catalítica como a temperatura, por isso explica-se a interação entre tempo e temperatura, no caso esta é formada de reações complexas divididas nas etapas de iniciação, propagação e terminação. O aparecimento dos compostos detectados na extinção específica a $270 \mathrm{~nm}$ ocorre na etapa final denominada terminação (Silva et al., 2012). 
Research, Society and Development, v. 11, n. 2, e31311225685, 2022

(CC BY 4.0) | ISSN 2525-3409 | DOI: http://dx.doi.org/10.33448/rsd-v11i2.25685

Tabela 6. Influência da temperatura e luminosidade sobre extinção específica a $232 \mathrm{~nm}$.

\begin{tabular}{|c|c|c|c|c|c|c|c|c|c|}
\hline \multirow{2}{*}{\multicolumn{2}{|c|}{$\begin{array}{c}\text { Dias } \\
\text { Luminosidade (Lux) }\end{array}$}} & \multirow{2}{*}{\multicolumn{2}{|c|}{$\begin{aligned} \text { Zero } \\
300\end{aligned}$}} & \multicolumn{2}{|c|}{30} & \multicolumn{2}{|c|}{60} & \multicolumn{2}{|c|}{90} \\
\hline & & & & 0 & 300 & 0 & 300 & 0 & 300 \\
\hline \multirow{2}{*}{$\begin{array}{c}\text { Temperatura } \\
\left({ }^{\circ} \mathbf{C}\right)\end{array}$} & 23 & \multirow{2}{*}{\multicolumn{2}{|c|}{$2,48 \pm 0,15$}} & $2,73 \pm 0,06 \mathrm{Ba}$ & $3,05 \pm 0,01 * \mathrm{Ab}$ & $2,84 \pm 0,01 * \mathrm{Bb}$ & $3,05 \pm 0,16^{*} \mathrm{Aa}$ & $2,86 \pm 0,16 * \mathrm{Ba}$ & $3,20 \pm 0,13 * \mathrm{Aa}$ \\
\hline & 30 & & & $2,92 \pm 0,11^{*} \mathrm{Aa}$ & $3,13 \pm 0,03^{*} \mathrm{Aa}$ & $2,95 \pm 0,02 * \mathrm{Aa}$ & $3,13 \pm 0,06^{*} \mathrm{Aa}$ & $3,00 \pm 0,04 * \mathrm{Aa}$ & $3,28 \pm 0,12 * \mathrm{Aa}$ \\
\hline
\end{tabular}

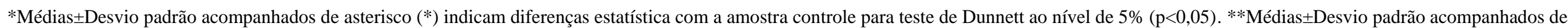

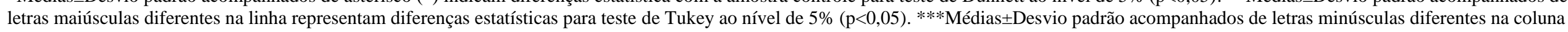
representam diferenças estatísticas para teste de Tukey ao nível de $5 \%(\mathrm{p}<0,05)$. Fonte: Autores.

Tabela 7. Influência da temperatura e luminosidade sobre extinção específica a $270 \mathrm{~nm}$.

Dias

Zero

\section{0}

0
90

\begin{tabular}{|c|c|c|c|c|c|c|c|c|}
\hline Luminosidade (I & & 300 & 0 & 300 & 0 & 300 & 0 & 300 \\
\hline \multirow{2}{*}{ Temperatura $\left({ }^{\circ} \mathbf{C}\right)$} & 23 & \multirow{2}{*}{$0,15 \pm 0,01$} & $0,11 \pm 0,01 * \mathrm{Ba}$ & $0,16 \pm 0,01 \mathrm{Aa}$ & $0,12 \pm 0,01 \mathrm{Bb}$ & $0,17 \pm 0,01 * \mathrm{Aa}$ & $0,12 \pm 0,01 * \mathrm{Ba}$ & $0,18 \pm 0,02 * \mathrm{Aa}$ \\
\hline & 30 & & $0,11 \pm 0,01 * \mathrm{Ba}$ & $0,16 \pm 0,01 \mathrm{Aa}$ & $0,13 \pm 0,01 \mathrm{Ba}$ & $0,21 \pm 0,01 * \mathrm{Aa}$ & $0,15 \pm 0,01 \mathrm{Ba}$ & $0,23 \pm 0,01 * \mathrm{Aa}$ \\
\hline
\end{tabular}

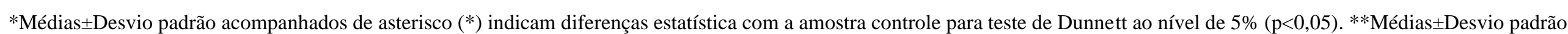

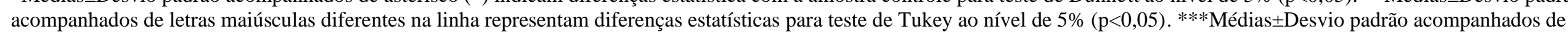
letras minúsculas diferentes na coluna representam diferenças estatísticas para teste de Tukey ao nível de 5\% (p<0,05). Fonte: Autores. 


\subsection{Fenóis totais}

Na Tabela 8 pode-se observar que a diferença estatística para Tukey a 5\% para os resultados de fenóis totais ocorreu em função da luminosidade aos 60 dias de experimento. Adicionando-se o fator tempo ao tratamento (Figura 5), as diferenças estatísticas foram observadas para a variável luminosidade, ocasionando um efeito negativo sobre o teor de fenóis totais.

Figura 5. Diagrama de Pareto para influência da tempo, temperatura e luminosidade sobre fenóis totais.

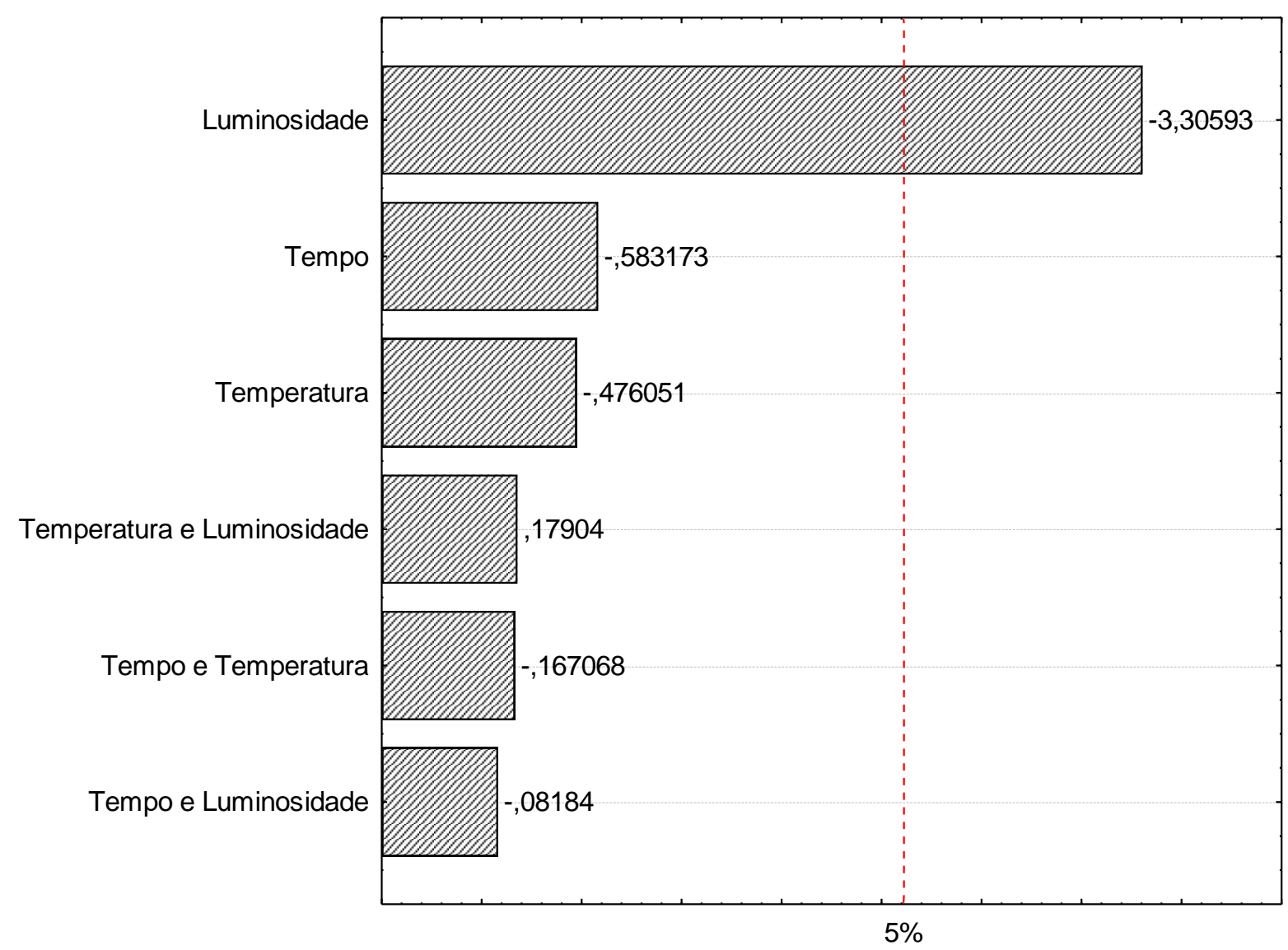

Fonte: Autores.

A sensibilidade quanto a presença de luminosidade para os compostos fenólicos se dá em razão da presença das ligações duplas que estes compostos possuem, tornando-os alvos de radicais livres, que em presença de luminosidade possuem maior pronunciamento e atacam diretamente as ligações duplas em busca de alcançarem o emparelhamento energético e tornarem-se moléculas estáveis (Barreiros et al., 2006). 
Research, Society and Development, v. 11, n. 2, e31311225685, 2022

(CC BY 4.0) | ISSN 2525-3409 | DOI: http://dx.doi.org/10.33448/rsd-v11i2.25685

Tabela 8. Influência da temperatura e luminosidade sobre fenóis totais.

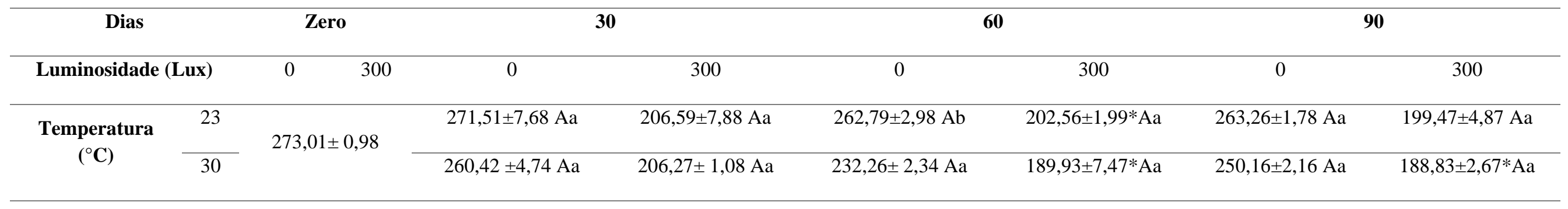

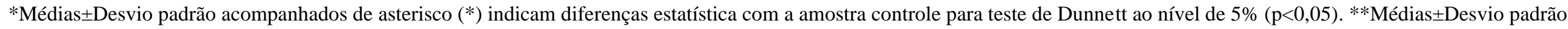

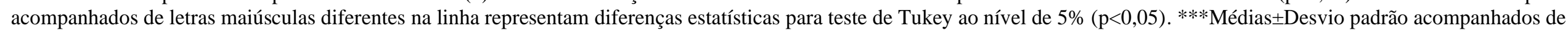
letras minúsculas diferentes na coluna representam diferenças estatísticas para teste de Tukey ao nível de 5\% (p<0,05). Fonte: Autores. 


\subsubsection{Carotenoides totais}

De acordo com a Tabela 9, quando avaliados os efeitos individuais da temperatura e luminosidade, somente a luminosidade exerceu influência significativa para Tukey a 5\%. Quando avaliada a influência do tempo, temperatura e luminosidade (Figura 6) obteve-se diferença significativa para Tukey a 5\% para o fator luminosidade e a interações entre tempo e temperatura e tempo e luminosidade.

Figura 6. Diagrama de Pareto para influência do tempo, temperatura e luminosidade sobre carotenoides totais.

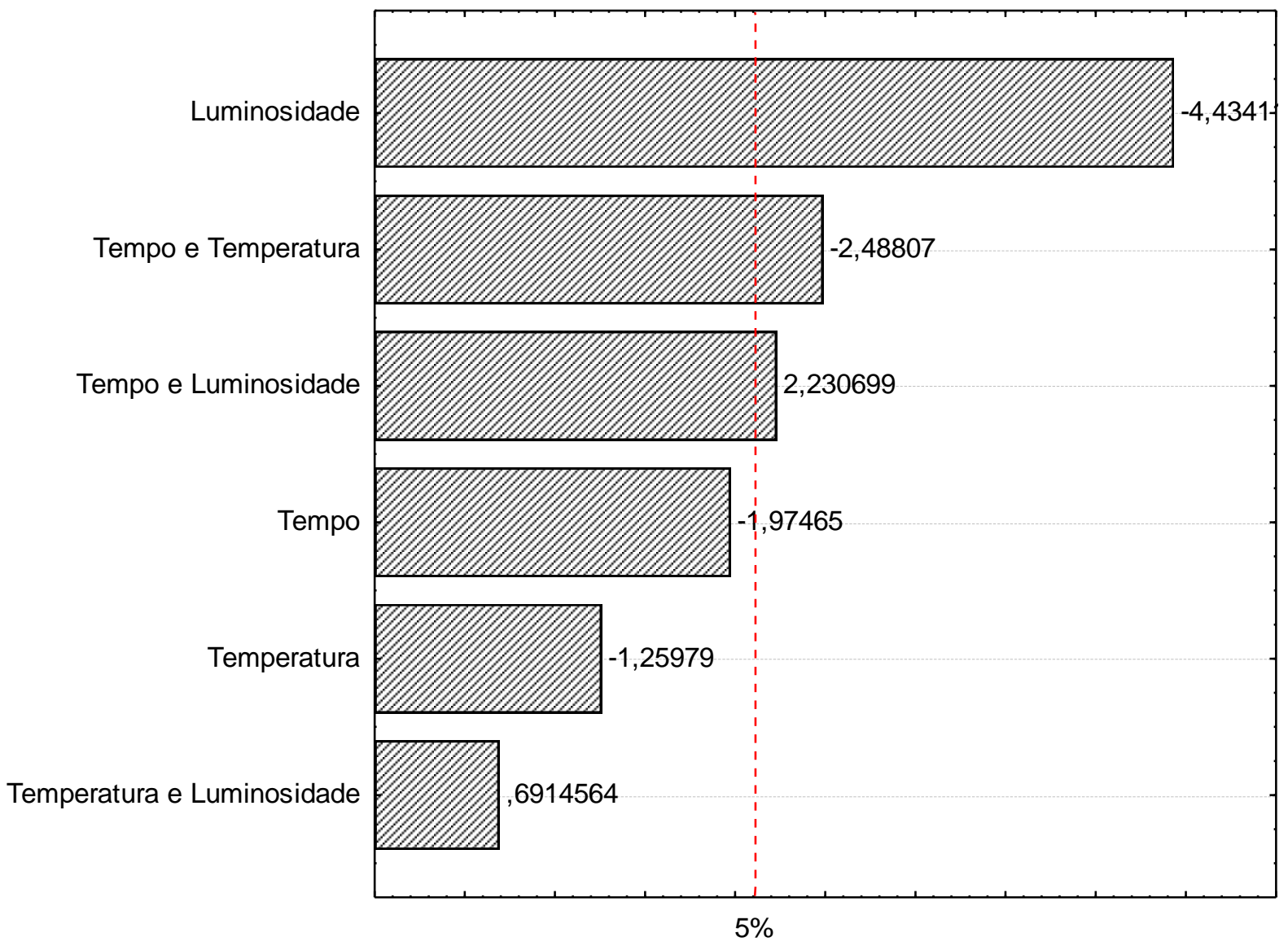

Fonte: Autores.

Segundo Uenojo et al. (2007), o efeito da luminosidade, oxidação e temperatura sobre os carotenoides agem como degradantes. A influência da luz sobre $\beta$-caroteno em 30 minutos de exposição, fez com a concentração inicial se reduzisse a metade. Na ausência de luminosidade e com temperatura ambiente, a velocidade de degradação de carotenoides mostra-se ocorrer mais lentamente, porém a medida em que há incremento no valor de temperatura, há concomitantemente aumento de cinética de degradativa. Os carotenoides são facilmente oxidados em presença de luminosidade em função do número grande de duplas ligações conjugadas (Ribeiro \& Seravalli, 2004). Essa estrutura insaturada dos carotenoides, os tornam altamente instáveis, biodisponíveis para ocorrer a isomerização e oxidação destes em presença também de aquecimento (Zepka, 2009).

A isomerização de carotenoides transforma a forma trans em cis que é menos estável termodinamicamente que a primeira citada. Isso acontece pelo fato da forma cis possuir dois grupamentos ou composto químico de um mesmo lado, promovendo repulsão entre pares eletrônicos de substituintes e um momento dipolar diferente de zero, ao passo que a configuração trans é mais estável, porque a repulsão entre seus pares promove um momento dipolar nulo, dando maior condição de estabilidade à estrutura. Os compostos da classe dos carotenoides com maior atividade biológica são os que 
Research, Society and Development, v. 11, n. 2, e31311225685, 2022

(CC BY 4.0) | ISSN 2525-3409 | DOI: http://dx.doi.org/10.33448/rsd-v11i2.25685

possuem todas as ligações na forma de isômero trans (Morais, 2006). Já o processo de oxidação dos carotenoides se dá em função de sua própria capacidade de supressão de moléculas de oxigênio singlete presentes em maior quantidade em azeites expostos a luminosidade pela ação das clorofilas. A desativação física da espécie reativa envolve transferência de energia excitada do oxigênio singlete para o carotenoide, resultando em formação de oxigênio no estado fundamental e carotenoide no estado triplete. O composto pode dissipar a energia através de interações vibracionais, sem ocorrência de degradação, porém esta ação vibracional pode acarretar em cisão de ligações duplas, dando origem a compostos secundários sem ação biológica (Ronsein et al., 2006). 
Research, Society and Development, v. 11, n. 2, e31311225685, 2022

(CC BY 4.0) | ISSN 2525-3409 | DOI: http://dx.doi.org/10.33448/rsd-v11i2.25685

Tabela 9. Influência da temperatura e luminosidade em carotenoides totais.

\begin{tabular}{|c|c|c|c|c|c|c|c|c|c|}
\hline \multirow{2}{*}{\multicolumn{2}{|c|}{$\begin{array}{c}\text { Dias } \\
\text { Luminosidade (Lux) }\end{array}$}} & \multirow{2}{*}{\multicolumn{2}{|c|}{$\begin{array}{l}\text { Zero } \\
300\end{array}$}} & \multicolumn{2}{|c|}{30} & \multicolumn{2}{|c|}{60} & \multicolumn{2}{|c|}{90} \\
\hline & & & & 0 & 300 & 0 & 300 & 0 & 300 \\
\hline \multirow{2}{*}{$\begin{array}{c}\text { Temperatura } \\
\left({ }^{\circ} \mathbf{C}\right)\end{array}$} & 23 & \multirow{2}{*}{\multicolumn{2}{|c|}{$11,81 \pm 0,75$}} & $11,49 \pm 0,18 \mathrm{Aa}$ & $8,62 \pm 1,14 * \mathrm{Ba}$ & $10,71 \pm 1,05 \mathrm{Aa}$ & $8,75 \pm 1,59 * \mathrm{Ba}$ & $10,94 \pm 1,08 \mathrm{Aa}$ & $9,59 \pm 0,95 \mathrm{Ba}$ \\
\hline & 30 & & & $11,87 \pm 0,30 \mathrm{Aa}$ & $9,25 \pm 0,66 * \mathrm{Ba}$ & $10,45 \pm 0,16 \mathrm{Aa}$ & $7,93 \pm 0,24 * \mathrm{Ba}$ & $8,95 \pm 0,92 * \mathrm{Aa}$ & $8,49 \pm 0,94 * \mathrm{Ba}$ \\
\hline
\end{tabular}

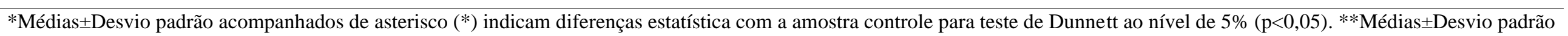

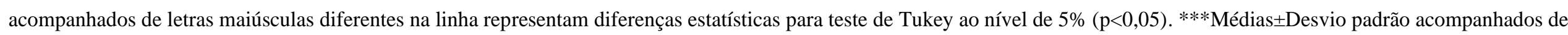
letras minúsculas diferentes na coluna representam diferenças estatísticas para teste de Tukey ao nível de 5\% (p<0,05). Fonte: Autores. 


\subsubsection{Clorofilas totais}

De acordo com a Tabela 10 quando observados os efeitos dos fatores temperatura e luminosidade em cada intervalo de tempo, somente a luminosidade mostrou-se significativa para Tukey a 5\%, porém quando analisa-se a influência do tempo de armazenamento em conjunto com a luminosidade e temperatura (Figura 7) resultou em diferenças significativas para tempo, interação entre tempo e temperatura, luminosidade, temperatura e interação entre tempo e luminosidade para Tukey a 5\%.

Figura 7. Diagrama de Pareto para influência da tempo, temperatura e luminosidade sobre clorofilas totais.

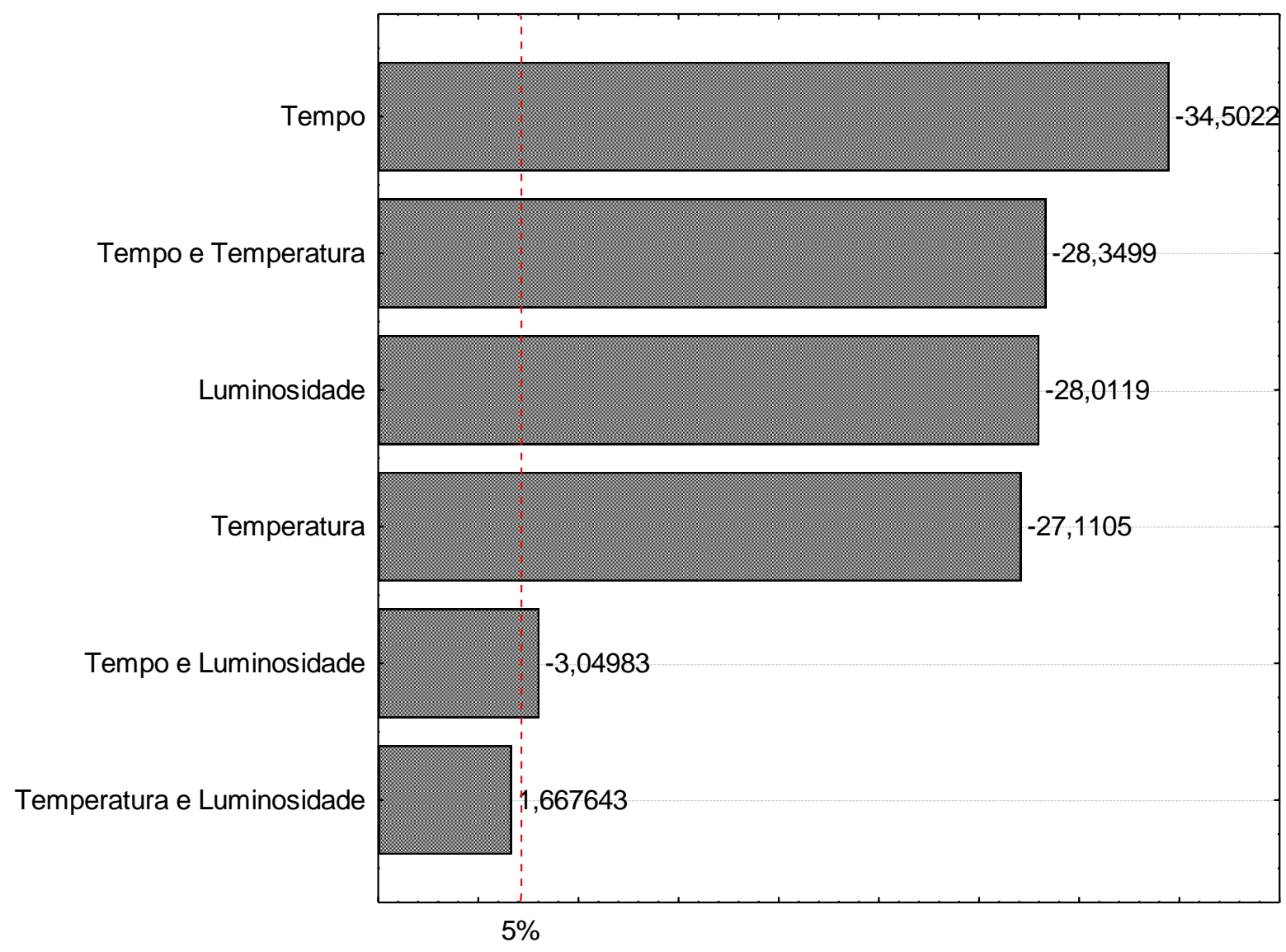

Fonte: Autores.

Segundo Romano (2001) as plantas utilizam radiação fotossintetizante ativa, situada entre os comprimentos de onda de 390 a 760 nm (luz visível). Uma única molécula de clorofila pode absover 1 quantum de energia de cada vez, resultando na excitação de qualquer elétron de um dos átomos da molécula. Os elétrons presentes em orbitais estáveis do átomo recebem esta energia e deslocam-se para orbitais mais distantes do núcleo, distância esta que é proporcional à energia de um fóton que absorveu. A molécula encontra-se, portanto em estado excitado, sendo esta energia utilizada para fotossíntese.

O estresse causado na planta pela incidência de luminosidade pode causar o processo de auto-destruição da clorofila, denominado de foto-oxidação. Tal processo é irreversível, fazendo com que os pigmentos ao absorveram esta energia fiquem excitados durante um grande espaço de tempo, interagindo com o oxigênio atmosférico e produzindo oxigênio singlete, ao mesmo tempo que se degrada neste processo de troca energética formando feofitinas e feoforbídeos (Streit et al., 2005; Taiz \& Zieger, 2017). Com isso, pode-se estabelecer uma relação entre a diminuição do conteúdo de clorofilas para as amostras expostas a 300 Lux no decorrer do experimento. 
Research, Society and Development, v. 11, n. 2, e31311225685, 2022

(CC BY 4.0) | ISSN 2525-3409 | DOI: http://dx.doi.org/10.33448/rsd-v11i2.25685

A ação da temperatura impactou negativamente no conteúdo de clorofilas totais, assim como os outros fatores, causando um decréscimo. Tal fato pode ser elucidado através do aumento de temperatura causado em decorrência do processamento térmico de vegetais. A principal via de degradação da clorofila através do aumento de temperatura se dá em função da substituição do átomo de magnésio por dois átomos de hidrogênio, processo que é denominado de feofitinização. Tal reação é catalisada por meio do aumento da acidez do meio que influencia na perda do $\mathrm{Mg}^{2+}$. As feofitinas possuem coloração aproximada de verde oliva ao amarelo, são susceptíveis a hidrólise, resultando na liberação de molécula de fitol, originando uma molécula denominada de feoforbídeo que acentua a coloração do amarelo para o marrom do azeite (Lanfer-Marquez, 2003). 
Research, Society and Development, v. 11, n. 2, e31311225685, 2022

(CC BY 4.0) | ISSN 2525-3409 | DOI: http://dx.doi.org/10.33448/rsd-v11i2.25685

Tabela 10. Influência da temperatura e luminosidade sobre clorofilas totais.

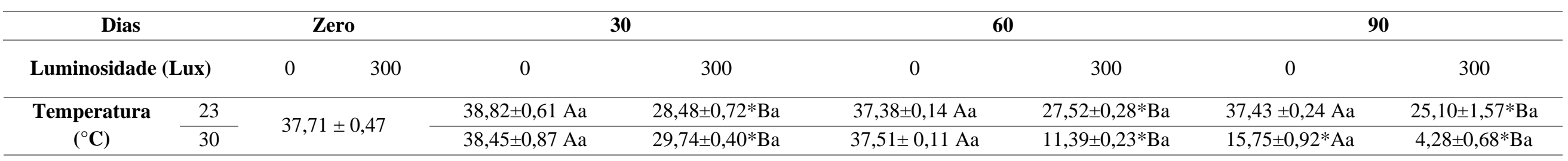

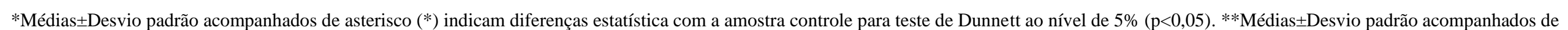

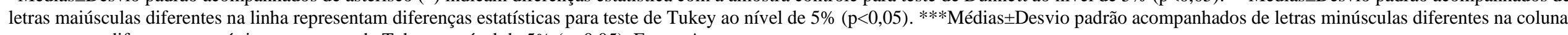
representam diferenças estatísticas para teste de Tukey ao nível de 5\% (p<0,05). Fonte: Autores. 


\subsubsection{Atividade antioxidante}

$\mathrm{Na}$ Tabela 11 pode-se observar que os efeitos individuais da temperatura e luminosidade não ocasionaram diferenças estatísticas para Tukey a 5\%, porém analisando-se o fator tempo (Figura 8) pode-se determinar a influência deste impactando negativamente sobre a atividade antioxidante das amostras analisadas.

Figura 8. Diagrama de Pareto para influência da tempo, temperatura e luminosidade sobre atividade antioxidante.

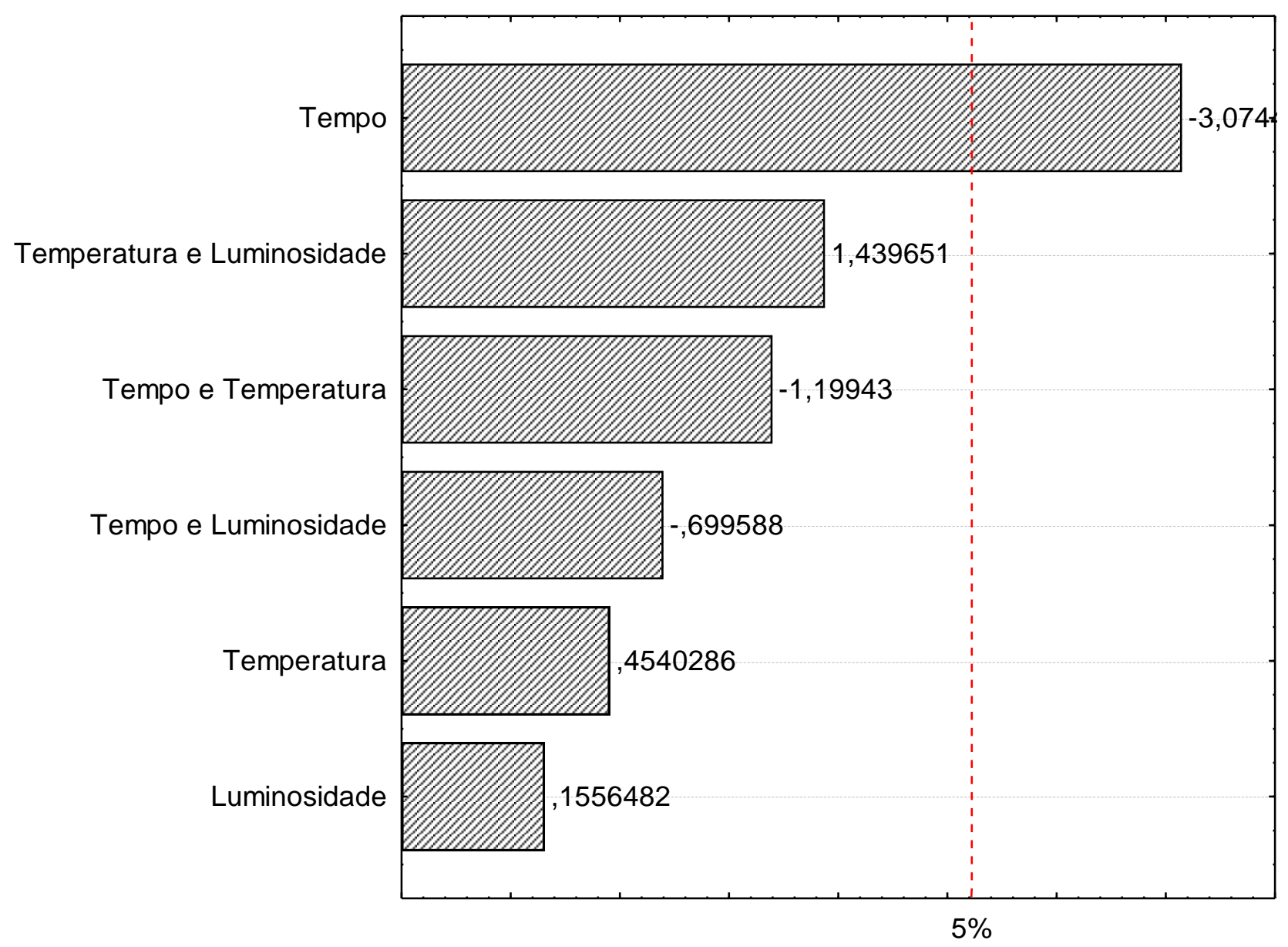

Fonte: Autores.

A ocorrência da diminuição da atividade antioxidante em função do tempo pode ser explicada através da também diminuição do teor de fenóis totais e carotenoides totais das amostras em função de processos catalíticos ou sinérgicos do armazenamento no decorrer do intervalo de realização do experimento. 
Research, Society and Development, v. 11, n. 2, e31311225685, 2022

(CC BY 4.0) | ISSN 2525-3409 | DOI: http://dx.doi.org/10.33448/rsd-v11i2.25685

Tabela 11. Influência da temperatura e luminosidade sobre atividade antioxidante.

\begin{tabular}{|c|c|c|c|c|c|c|c|c|c|}
\hline \multirow{2}{*}{\multicolumn{2}{|c|}{$\begin{array}{c}\text { Dias } \\
\text { Luminosidade (Lux) }\end{array}$}} & \multicolumn{2}{|c|}{ Zero } & \multicolumn{2}{|c|}{30} & \multicolumn{2}{|c|}{60} & \multicolumn{2}{|c|}{90} \\
\hline & & 0 & 300 & 0 & 300 & 0 & 300 & 0 & 300 \\
\hline \multirow{2}{*}{$\begin{array}{c}\text { Temperatura } \\
\left({ }^{\circ} \mathbf{C}\right)\end{array}$} & 23 & \multirow{2}{*}{\multicolumn{2}{|c|}{$24,39 \pm 0,53$}} & $22,35 \pm 0,92 \mathrm{Aa}$ & $21,19 \pm 1,64 \mathrm{Aa}$ & $18,32 \pm 0,99 * \mathrm{Aa}$ & $18,42 \pm 1,36 * \mathrm{Aa}$ & $20,74 \pm 1,71 * \mathrm{Aa}$ & $19,94 \pm 0,67 * \mathrm{Aa}$ \\
\hline & 30 & & & $21,60 \pm 2,31 \mathrm{Aa}$ & $24,27 \pm 2,31 \mathrm{Aa}$ & $22,59 \pm 3,92 \mathrm{Aa}$ & $17,03 \pm 0,81 * \mathrm{Aa}$ & $19,79 \pm 0,55^{*} \mathrm{Aa}$ & $19,76 \pm 0,92 * \mathrm{Aa}$ \\
\hline
\end{tabular}

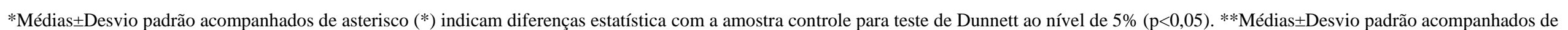

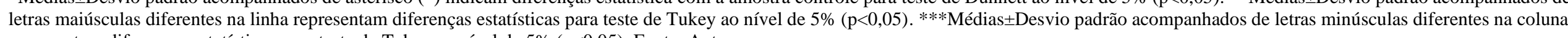
representam diferenças estatísticas para teste de Tukey ao nível de $5 \%(\mathrm{p}<0,05)$. Fonte: Autores. 


\subsubsection{Análise Sensorial}

No teste de aceitabilidade do aroma, através da Tabela 12, pode-se verificar que não ocorreram diferenças significativas para Tukey a 5\%.

Para o teste de aceitabilidade do sabor (Tabela 13), as diferenças estatísticas para Tukey a 5\% apresentaram-se aos 30 dias de experimento também no quesito luminosidade. O tratamento que recebeu luminosidade de 300 Lux e temperatura de $30^{\circ} \mathrm{C}$ foi o menos aceito quanto ao sabor. Tal fato também se explica pela formação de compostos secundários de oxidação (off flavours) que possuem sabor desagradável e tem sua origem catalisada pela presença da luminosidade em associação à clorofila e aumento das moléculas de oxigênio singlete. Muitas vezes os off flavours desenvolvidos durante esta etapa, servem de aviso de que o alimento não é mais comestível. Isto acontece em função da formação de hidroperóxidos, que apesar de serem não voláteis e inodoros, são totalmente instáveis, decompondo-se em reações ou espontaneamente para formar compostos voláteis. A natureza de um off flavourdepende também da composição de ácidos graxos e grau de oxidação de um óleo. Alguns exemplos de off flavours produtos da oxidação são os sabores de feijão cru, mais comuns para óleos de soja, sabores de peixe em óleo de pescado e sabores metálicos na gordura do leite. Acrescenta-se o fato de que a luminosidade também foi causa da diminuição dos teores de compostos fenólicos, diminuindo o amargor característico do azeite de oliva e esperado por grande parte dos julgadores (Brasil, 2014).

No teste de intenção de compra, (Tabela 14), as diferenças estatísticas também foram acompanhadas aos 30 dias de experimento para os tratamentos em 0 e 300 Lux, na temperatura de $30^{\circ} \mathrm{C}$, afetados pela mudança de sabor ocasionada pela presença de luminosidade, ou seja, o tratamento exposto a luminosidade de 300 Lux apresentou menor intenção de compra do que o exposto a 0 Lux (ausência) à mesma temperatura, provavelmente influenciado pelo sabor menos aceitável indicado no primeiro teste. 
Research, Society and Development, v. 11, n. 2, e31311225685, 2022

(CC BY 4.0) | ISSN 2525-3409 | DOI: http://dx.doi.org/10.33448/rsd-v11i2.25685

Tabela 12. Aceitabilidade do aroma.

\begin{tabular}{|c|c|c|c|c|c|c|c|c|}
\hline \multirow{2}{*}{\multicolumn{2}{|c|}{$\begin{array}{c}\text { Dias } \\
\text { Luminosidade (Lux) }\end{array}$}} & Zero & \multicolumn{2}{|c|}{30} & \multicolumn{2}{|c|}{60} & \multicolumn{2}{|c|}{90} \\
\hline & & 300 & 0 & 300 & 0 & 300 & 0 & 300 \\
\hline Temperatura & 23 & \multirow{2}{*}{$6,75 \pm 1,99$} & $6,89 \pm 1,20 \mathrm{Aa}$ & $6,91 \pm 1,31 \mathrm{Aa}$ & $6,90 \pm 1,86 \mathrm{Aa}$ & $6,75 \pm 1,74 \mathrm{Aa}$ & $7,26 \pm 1,91 \mathrm{Aa}$ & $7,15 \pm 1,60 \mathrm{Aa}$ \\
\hline$\left({ }^{\circ} \mathbf{C}\right)$ & 30 & & $6,84 \pm 1,65 \mathrm{Aa}$ & $6,73 \pm 1,24 \mathrm{Aa}$ & $6,63 \pm 1,73 \mathrm{Aa}$ & $6,48 \pm 1,74 \mathrm{Aa}$ & $6,42 \pm 1,59 \mathrm{Aa}$ & $6,31 \pm 1,52 \mathrm{Aa}$ \\
\hline
\end{tabular}

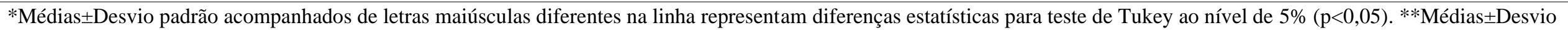
padrão acompanhados de letras minúsculas diferentes na coluna representam diferenças estatísticas para teste de Tukey ao nível de 5\% (p<0,05). Fonte: Autores.

Tabela 13. Aceitabilidade do sabor.

\begin{tabular}{|c|c|c|c|c|c|c|c|c|c|}
\hline Dias & & \multicolumn{2}{|c|}{ Zero } & \multicolumn{2}{|c|}{30} & \multicolumn{2}{|c|}{60} & \multicolumn{2}{|c|}{90} \\
\hline \multicolumn{2}{|c|}{ Luminosidade (Lux) } & 0 & 300 & 0 & 300 & 0 & 300 & 0 & 300 \\
\hline \multirow{2}{*}{$\begin{array}{c}\text { Temperatura } \\
\left({ }^{\circ} \mathbf{C}\right)\end{array}$} & 23 & \multirow{2}{*}{\multicolumn{2}{|c|}{$6,58 \pm 1,89$}} & $7,00 \pm 1,58 \mathrm{Aa}$ & $6,63 \pm 1,57 \mathrm{Ba}$ & $6,66 \pm 1,64 \mathrm{Aa}$ & $6,18 \pm 1,96 \mathrm{Aa}$ & $6,52 \pm 2,30 \mathrm{Aa}$ & $6,68 \pm 1,92 \mathrm{Aa}$ \\
\hline & 30 & & & $6,42 \pm 1,72 \mathrm{Aa}$ & $6,08 \pm 1,63 \mathrm{Ab}$ & $6,60 \pm 1,63 \mathrm{Aa}$ & $5,96 \pm 2,06 \mathrm{Aa}$ & $6,36 \pm 1,62 \mathrm{Aa}$ & $6,42 \pm 1,91 \mathrm{Aa}$ \\
\hline
\end{tabular}

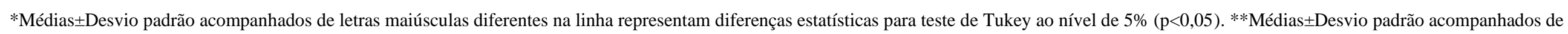
letras minúsculas diferentes na coluna representam diferenças estatísticas para teste de Tukey ao nível de $5 \%$ ( $p<0,05)$. Fonte: Autores.

Tabela 14. Intenção de compra.

\begin{tabular}{|c|c|c|c|c|c|c|c|c|c|}
\hline \multirow{2}{*}{\multicolumn{2}{|c|}{$\begin{array}{c}\text { Dias } \\
\text { Luminosidade (Lux) }\end{array}$}} & \multirow{2}{*}{\multicolumn{2}{|c|}{$\begin{array}{lr} & \text { Zero } \\
& \\
0 & 300\end{array}$}} & \multicolumn{2}{|c|}{30} & \multicolumn{2}{|c|}{60} & \multicolumn{2}{|c|}{90} \\
\hline & & & & 0 & 300 & 0 & 300 & 0 & 300 \\
\hline \multirow{2}{*}{$\begin{array}{c}\text { Temperatura } \\
\left({ }^{\circ} \mathbf{C}\right)\end{array}$} & 23 & \multirow{2}{*}{\multicolumn{2}{|c|}{$3,75 \pm 0,95$}} & $3,91 \pm 1,03 \mathrm{Aa}$ & $3,52 \pm 1,07 \mathrm{Aa}$ & $3,57 \pm 1,04 \mathrm{Aa}$ & $3,42 \pm 1,15 \mathrm{Aa}$ & $3,68 \pm 1,33 \mathrm{Aa}$ & $3,84 \pm 1,03 \mathrm{Aa}$ \\
\hline & 30 & & & $3,54 \pm 1,05 \mathrm{Aa}$ & $3,36 \pm 0,91 \mathrm{Ab}$ & $3,36 \pm 0,94 \mathrm{Aa}$ & $3,27 \pm 1,35 \mathrm{Aa}$ & $3,57 \pm 0,81 \mathrm{Aa}$ & $3,31 \pm 1,25 \mathrm{Aa}$ \\
\hline
\end{tabular}

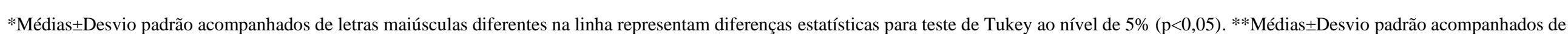
letras minúsculas diferentes na coluna representam diferenças estatísticas para teste de Tukey ao nível de $5 \%$ (p<0,05). Fonte: Autores. 


\section{Conclusão}

Os fatores tempo, temperatura e luminosidade impactaram de forma sobre a constituição física, química e sensorial do azeite de oliva. A presença de luminosidade propiciou o aumento da acidez livre e os valores para as duas extinções específicas no ultravioleta, ao passo que diminuiu o teor de fenóis totais, carotenoides e clorofilas totais. A temperatura agiu de forma semelhante, visto que o incremento de em torno de $7^{\circ} \mathrm{C}$ durante o armazenamento causou o aumento da acidez livre e da extinção específica a $232 \mathrm{~nm}$, auxiliando na diminuição do teor de carotenoides e clorofilas.

De igual forma, corroborou-se que os fatores empregados durante o tempo de armazenamento impactam diretamente na qualidade do azeite de oliva, uma vez que o fator tempo agiu de forma significante sobre o valor de acidez livre, índice de peróxidos, extinção específica, carotenoides totais, clorofilas totais e atividade antioxidante. Na análise sensorial pode-se observar que mesmo se tratando de julgadores não treinados, estes puderam observar as diferenças significativas entre o armazenamento com diferentes luminosidades e seus impactos sobre a qualidade do produto comercializado, causando diminuição da intenção de compra.

\section{Agradecimentos}

Ao Programa de Apoio aos Pólos Tecnológicos - Secretaria da Ciência, Inovação e Desenvolvimento Tecnológico do Estado do Rio Grande do Sul e Banco Mundial e Laboratório de Desenvolvimento Tecnológico e Inovação aplicados aos olivais da Região da Campanha na Universidade Federal do Pampa - UNIPAMPA.

\section{Referências}

Andrade, D., Dias, C. S., da Silva Pereira, M., Salim, C. D., \& Crexi, V. T. (2017). Azeite de oliva da região da campanha: padrões de identidade e qualidade. Anais do Salão Internacional de Ensino, Pesquisa e Extensão, 9(2).

Ayton, J., Mailer, R. J., \& Graham, K. (2012). The effect of storage conditions on extra virgin olive oil quality. RIRDC.

Bakhouche, A., Lozano-Sánchez, J., Fernández-Gutiérrez, A., \& Segura Carretero, A. (2015). Trends in chemical characterization of virgin olive oil phenolic profile: An overview and new challenges. Olivae, 122, 3-15.

Barreiros, A. L., David, J. M., \& David, J. P. (2006). Estresse oxidativo: relação entre geração de espécies reativas e defesa do organismo. Química nova, 29, $113-123$.

Bertoncini, E. I., \& Testa, U. (2014). Análise sensorial de azeites de oliva. Informe Agropecuário, 35(282), 58-65.

Boskou, D., Blekas, G., \& Tsimidou, M. (2006). Olive oil composition. In Olive Oil (pp. 41-72). AOCS press.

Brand-Williams, W., Cuvelier, M. E., \& Berset, C. L. W. T. (1995). Use of a free radical method to evaluate antioxidant activity. LWT-Food science and Technology, 28(1), 25-30.

Brasil, F. I. (2014). Os tipos e os efeitos da rancidez oxidativa em alimentos. Rancidez Oxidativa, (29), 42-49.

Brasil. Instrução Normativa ${ }^{\circ}$ 1, de 30 de janeiro de 2012. Dispõe sobre o regulamento técnico do azeite de oliva e do óleo de bagaço de oliva. Diário Oficial [da] República Federativa do Brasil, Brasília, DF, v. 126, n. 23, $1^{\circ}$ fev.2012. Seção 1, parte 1, p. 1-8.

Cardoso, L. G. V., Barcelos, M. D. F. P., de Oliveira, A. F., Pereira, J. D. A. R., de Abreu, W. C., de Araujo Pimentel, F., \& de Angelis Pereira, M. C. (2010). Características físico-químicas e perfil de ácidos graxos de azeites obtidos de diferentes variedades de oliveiras introduzidas no Sul de Minas GeraisBrasil. Semina: Ciências Agrárias, 31(1), 127-135.

Choe, E., Lee, J., \& Min, D. B. (2019). Chemistry for oxidative stability of edible oils. Healthful lipids, 558-590.

Conselho Oleícola Internacional (2021) Brazil olive oil imports: Brazil olive oil distribution. https://www.internationaloliveoil.org/wpcontent/uploads/2021/02/IOC-Import-profiles-Brazil-2019-20-rev0.html\#brazil-olive-oil-distribution>.

Conselho Oleícola Internacional (2021). Trade standard applying to olive oils and olive pomace oils. https://www.internationaloliveoil.org/what-wedo/chemistry-standardisation-unit/standards-and-methods/>.

Coutinho, E. F. (2007). A cultura da Oliveira. Embrapa Clima Temperado.

Coutinho, E. F., \& Jorge, R. O. (2007). A cultura da Oliveira (Cap. 2, pp. 19-29). Embrapa Clima Temperado. 
Dabbou, S., Rjiba, I., Nakbi, A., Gazzah, N., Issaoui, M., \& Hammami, M. (2010). Compositional quality of virgin olive oils from cultivars introduced in Tunisian arid zones in comparison to Chemlali cultivars. Scientia Horticulturae, 124(1), 122-127.

Dias, C. S., da Silva Rodrigues, R., Gonçalves, W. F., Jacques, A., Crexi, V. T., \& Azevedo, M. L. (2017). Composição fitoquímica do azeite e do bagaço de azeitona de uma agroindústria da Região da Campanha. Revista da Jornada de Pós-Graduação e Pesquisa-Congrega Urcamp, 951-960.

Fogaça, J. R. V. (2021). "Temperatura e Velocidade das Reações"; Brasil Escola. Disponível em: https://brasilescola.uol.com.br/quimica/temperaturavelocidade-das-reacoes.htm. Acesso em 09 de dezembro de 2021.

Freire, P. C. M., Mancini-Filho, J., \& Ferreira, T. A. P. D. C. (2013). Principais alterações físico-químicas em óleos e gorduras submetidos ao processo de fritura por imersão: regulamentação e efeitos na saúde. Revista de Nutrição, 26, 353-358.

Gorzynik-Debicka, M., Przychodzen, P., Cappello, F., Kuban-Jankowska, A., Marino Gammazza, A., Knap, N., \& Gorska-Ponikowska, M. (2018). Potential health benefits of olive oil and plant polyphenols. International journal of molecular sciences, 19(3), 686.

Herrera, B. J., \& Dueñas, A. C. (2008). La Cata de aceites: Aceite de oliva virgen. Copysevilla.

Instituto Adolfo Lutz (2008). Normas Analíticas do Instituto Adolfo Lutz. v. 1: Métodos químicos e físicos para análise de alimentos (4a ed.). São Paulo: IMESP.

Jorge, R. (2010). Caracterização de Azeites Virgem Extra "Gourmet" Varietais e "Blends" comercializados no Mercado do Rio Grande do Sul. Tese (Doutorado em Ciência e Tecnologia Agroindustrial), Faculdade de Agronomia Eliseu Maciel, Universidade Federal de Pelotas. Pelotas.

Kamal-Eldin, A., \& Pokorný, J. (Eds.). (2005). Analysis of lipid oxidation. AOCS press.

Laincer, F., Laribi, R., Tamendjari, A., Arrar, L., Rovellini, P., \& Venturini, S. (2014). Olive oils from Algeria: Phenolic compounds, antioxidant and antibacterial activities. Grasas y Aceites, 65(1), e001-e001.

Lanfer-Marquez, U. M. (2003). O papel da clorofila na alimentação humana: uma revisão. Revista Brasileira de Ciências Farmacêuticas, $39,227-242$.

Manai-Djebali, H., Krichène, D., Ouni, Y., Gallardo, L., Sánchez, J., Osorio, E., \& Zarrouk, M. (2012). Chemical profiles of five minor olive oil varieties grown in central Tunisia. Journal of Food Composition and Analysis, 27(2), 109-119.

Martins, B. (2015). Azeites Virgens: efeito da cultivar na composição química e estudo da adição de agentes para incremento de antioxidantes quando sujeitos a aquecimento em micro-ondas (Doctoral dissertation).

Mello, L. D., \& Pinheiro, M. F. (2012). Aspectos físico-químicos de azeites de oliva e de folhas de oliveira provenientes de cultivares do RS, Brasil. Alimentos e Nutrição, 23(4), 537-548.

Morais, F. L. D. (2006). Carotenoides: características biológicas e químicas.

Morales, M. T., \& Przybylski, R. (2003). Oxidación del aceite de oliva. Manual del aceite de oliva: Madrid: Mundi-Prensa, $442-474$.

Ochando-Pulido, J. M., Vellido-Pérez, J. A., González-Hernández, R., \& Martínez-Férez, A. (2020). Optimization and modeling of two-phase olive-oil washing wastewater integral treatment and phenolic compounds recovery by novel weak-base ion exchange resins. Separation and Purification Technology, 249, 117084.

Oliveira, D. A. L. D. (2014). Análise fisico-química de azeites produzidos em lagares da região do Algarve-Portugal (Doctoral dissertation).

Pokorny, J., Kalinova, L., \& Dysseler, P. (1995). Determination of chlorophyll pigments in crude vegetable oils: Results of a collaborative study and the standardized method (Technical Report). Pure and Applied Chemistry, 67(10), 1781-1787.

Reboredo-Rodríguez, P., González-Barreiro, C., Cancho-Grande, B., Valli, E., Bendini, A., Toschi, T. G., \& Simal-Gandara, J. (2016). Characterization of virgin olive oils produced with autochthonous Galician varieties. Food chemistry, 212, 162-171.

Ribeiro, E. P., \& Seravalli, E. A. G. (2004). Química de alimentos. São Paulo: E. Blucher.

Rodeghiero, J. M. (2016). Caracterização físico-química e atividade antioxidante de azeites de oliva produzidos no Rio Grande do Sul. Dissertação (Mestrado em Ciência e Tecnologia Agroindustrial). Faculdade de Agronomia Eliseu Maciel, Universidade Federal de Pelotas. Pelotas.

Rodriguez-Amaya, D. B. (2001). A guide to carotenoid analysis in foods.

Romano, M. R. (2011). Análise de crescimento, produção de biomassa, fotossíntese e biossíntese de aminoácidos em plantas transgênicas de tabaco (Nicotiana tabacum L.) que expressam o gene Lhcb1* 2 de ervilha (Doctoral dissertation, Universidade de São Paulo).

Ronsein, G. E., Miyamoto, S., Bechara, E., Di Mascio, P., \& Martinez, G. R. (2006). Oxidação de proteínas por oxigênio single te: mecanismos de dano, estratégias para detecção e implicações biológicas. Química Nova, 29(3), 563-568.

Silva, L. F. D. O. D., Oliveira, A. F. D., Pio, R., Alves, T. C., \& Zambon, C. R. (2012). Variação na qualidade do azeite em cultivares de oliveira. Bragantia, 71, 202-209.

Silva, S. F. (2011). Estabilidade de azeite de oliva extra virgem (Olea europaea) em diferentes sistemas de embalagem.

Singleton, V. L., \& Rossi, J. A. (1965). Colorimetry of total phenolics with phosphomolybdic-phosphotungstic acid reagents. American journal of Enology and Viticulture, 16(3), 144-158.

Streit, N. M., Canterle, L. P., Canto, M. W. D., \& Hecktheuer, L. H. H. (2005). As clorofilas. Ciência Rural, 35(3), $748-755$. 
Research, Society and Development, v. 11, n. 2, e31311225685, 2022

(CC BY 4.0) | ISSN 2525-3409 | DOI: http://dx.doi.org/10.33448/rsd-v11i2.25685

Taiz, L., Zeiger, E., Møller, I. M., \& Murphy, A. (2017). Fisiologia e desenvolvimento vegetal. Artmed Editora.

Uenojo, M., Maróstica Junior, M. R., \& Pastore, G. M. (2007). Carotenóides: propriedades, aplicações e biotransformação para formação de compostos de aroma. Química Nova, 30(3), 616-622.

Vichi, S., Pizzale, L., Conte, L. S., Buxaderas, S., \& López-Tamames, E. (2003). Solid-phase microextraction in the analysis of virgin olive oil volatile fraction: Modifications induced by oxidation and suitable markers of oxidative status. Journal of Agricultural and Food Chemistry, 51(22), 6564-6571.

Zepka, L. Q. (2009). Identificação dos compostos de degradação de carotenoides e avaliação do impacto sobre a cor e aroma em sistemas-modelo simuladores de suco de caju. 